\title{
SCIENTIFIC REPORTS

\section{OPEN Steroids originating from bacterial bile acid degradation affect Caenorhabditis elegans and indicate potential risks for the fauna of manured soils}

\begin{abstract}
M. N. Mendelski ${ }^{1}$, R. Dölling ${ }^{1}$, F. M. Feller ${ }^{2}$, D. Hoffmann ${ }^{1}$, L. Ramos Fangmeier ${ }^{1}$, K. C. Ludwig ${ }^{2,3}$, O. Yücel ${ }^{2}$, A. Mährlein ${ }^{2}$, R. J. Paul ${ }^{1} \&$ B. Philipp ${ }^{2}$

Bile acids are steroid compounds from the digestive tracts of vertebrates that enter agricultural environments in unusual high amounts with manure. Bacteria degrading bile acids can readily be isolated from soils and waters including agricultural areas. Under laboratory conditions, these bacteria transiently release steroid compounds as degradation intermediates into the environment. These compounds include androstadienediones (ADDs), which are $\mathrm{C}_{19}$-steroids with potential hormonal effects. Experiments with Caenorhabditis elegans showed that ADDs derived from bacterial bile acid degradation had effects on its tactile response, reproduction rate, and developmental speed. Additional experiments with a deletion mutant as well as transcriptomic analyses indicated that these effects might be conveyed by the putative testosterone receptor NHR-69. Soil microcosms showed that the natural microflora of agricultural soil is readily induced for bile acid degradation accompanied by the transient release of steroid intermediates. Establishment of a model system with a Pseudomonas strain and $C$. elegans in sand microcosms indicated transient release of ADDs during the course of bile acid degradation and negative effects on the reproduction rate of the nematode. This proof-of-principle study points at bacterial degradation of manure-derived bile acids as a potential and so-far overlooked risk for invertebrates in agricultural soils.
\end{abstract}

Manure is known for containing hormonally active steroid compounds that may affect animal life in highly fertilized agricultural areas ${ }^{1}$. Apart from hormonally active steroids like estrogens, manure also contains further steroid compounds such as bile acids ${ }^{2-4}$. Bile acids are steroid compounds derived from cholesterol, which are produced in the liver of vertebrates and serve as detergents for the solubilisation of water-insoluble nutrients in the intestine and as signalling molecules ${ }^{5-7}$. Although $90 \%$ of bile acids are recycled in the so-called enterohepatic cycle, a considerable amount of bile acids is excreted via faeces and urine, in case of humans $400-600 \mathrm{mg}$ per person and day ${ }^{8}$. Consequently, high amounts of bile acids can also be found in manure ${ }^{9,10}$. Cattle faeces contain $1 \mathrm{mg}$ cholic acid and $3 \mathrm{mg}$ deoxycholic acid per $\mathrm{g}$ and chicken faeces contain about $7.5 \mathrm{mg}$ chenodeoxycholic acid (CDC) per $\mathrm{g}^{2}$. Dissolved in $1 \mathrm{ml}$ water, this would yield $2 \mathrm{mM}$ cholic acid and $7 \mathrm{mM}$ deoxycholic acid or even $19 \mathrm{mM}$ CDC for cow or chicken manure, respectively. In run-off simulations of poultry manure, about $0.3 \mathrm{mM}$ deoxycholic acid and even $0.5 \mathrm{mM} \mathrm{CDC}$ were found 9 . In studies using bile acids as indicators for faecal contamination of rivers, up to $13 \mathrm{nM}$ lithocholic acid and $76 \mathrm{nM}$ deoxycholic acid were detected despite the high dilution in these environments ${ }^{10}$.

Upon excretion, bile acids are subject to bacterial degradation and transformation, and bile-acid degrading bacteria can easily be isolated from many environments ${ }^{11-13}$. The best-studied degradation pathway for bile

${ }^{1}$ Institute of Zoophysiology, University of Münster (WWU), Münster, Germany. ${ }^{2}$ Institute of Molecular Microbiology and Biotechnology, University of Münster (WWU), Münster, Germany. ${ }^{3}$ Present address: Institute for Pharmaceutical Microbiology, University Hospital Bonn, University of Bonn, Bonn, Germany. M. N. Mendelski, R. Dölling and F. M. Feller contributed equally. Correspondence and requests for materials should be addressed to B.P. (email: bodo. philipp@uni-muenster.de) 
acids is the so-called 9,10-seco-pathway of steroid degradation via $\Delta^{1,4}$-3-keto-intermediates ${ }^{14-17}$. Degradation is initiated by oxidation of the A-ring and splitting off the $\mathrm{C}_{5}$-carboxylic side chain yielding $\mathrm{C}_{19}$ steroids with $\Delta^{1,4}$ 3,17-diketo structure ${ }^{14,15,18,19}$, which are called androstadienediones (ADDs). ADDs are also central intermediates in the degradation of other steroids such as cholesterol and testosterone ${ }^{17,20}$ (Supplemental Fig. S1).The further degradation of ADDs proceeds by oxygenation of $\mathrm{C} 9$, which results in cleavage of the B-ring ${ }^{21,22}$. These so-called seco-steroids are further degraded to structures consisting of only the $\mathrm{C}$ - and D-rings, which are then broken down to central intermediates of energy metabolism ${ }^{23}$.

A characteristic feature of bile acid degradation in laboratory cultures is the transient extracellular accumulation of several intermediates such as $\mathrm{ADDs}^{11,12,24}$. As ADDs have androgenic effects on mammals ${ }^{25,26}$ and are related to the biosynthesis of testosterone and estrogen $s^{27,28}$, their unusually high release into the environment due to massive input of manure may have hormonal effects. Such effects have been proposed for fish populations from rivers receiving phytosterol-containing wastewaters from paper mills ${ }^{29-31}$. In addition, invertebrates, such as molluscs and nematodes, were reported to be affected by vertebrate-like steroid hormones ${ }^{32-35}$.

The high abundance and diversity of nematodes and their manifold interactions in many food webs make nematode assemblages useful indicators of ecosystem conditions ${ }^{36,37}$. Caenorhabditis elegans is a free living, non-parasitic nematode, which is particularly abundant in microbe-rich terrestrial environments, especially rotting plant matter ${ }^{38}$. It is not only an important model organism for molecular biology or pharmacology ${ }^{39}$ but also $^{\circ}$ an environmental indicator for investigating anthropogenic influences on ecosystems ${ }^{39-44}$.

Concerning the possibility of hormonal control by steroids, the genome of $C$. elegans is predicted to encode 284 nuclear hormone receptors (NHRs), with the human or fly genome encoding only 48 or 21 of them, respectively ${ }^{45,46}$. However, the ligands of C. elegans NHRs are yet unknown, with the exception of the steroid hormone receptor DAF- $12^{47}$. In contrast to wild type, where the application of testosterone altered behavioural responses of C. elegans (e.g. the gentle touch response), such effects of testosterone were not detected in the outcrossed $n h r-69$ (ok1926) deficient mutant strain ${ }^{48}$. As NHR-69 also showed the best matching sequence with the human androgen receptor (AR) ligand-binding domain, it was suggested that NHR-69 is a putative testosterone receptor and $n h r-69$ a putative ortholog of the human AR gene. Another report ${ }^{49}$ additionally showed the capacity of NHR- 69 to bind testosterone and also provided evidence that NHR-14 is an estrogenic hormone receptor. Steroid hormone synthesis requires cholesterol. C. elegans, however, is cholesterol auxotrophic, which means that cholesterol must be absorbed with the feed (e.g., yeast/plant leftovers, animal faeces) ${ }^{50,51}$. Ingested cholesterol is then used, inter alia, for the synthesis of $\Delta^{4}$ - and $\Delta^{7}$-dafachronic acid (DA), which are the two known bile acid-like steroids that bind to DAF- $12^{52}$.

Given the fact of an overfertilization of arable soil by manure, this study aimed at an investigation of the bacterial degradation products of bile acids (i.e., ADD intermediates) and their effects on invertebrates from microbe-rich terrestrial environments, using C. elegans as an intensely studied representative.

\section{Results}

Effects of testosterone and ADDs on the gentle touch response of wild type and $n h r-69 \Delta$. Caenorhabditis elegans wild type (Fig. 1a,b) or $n h r-69 \Delta$ ( $n h r-69$ (ok1926) deficient mutant) (Fig. 1c,d) developed from egg to the late L4 larval stage under control or test conditions (exposure to $5 \mu \mathrm{M}$ of testosterone, ADD, $7 \alpha$-HADD, $12 \beta$-HADD, and 12 $\beta$-DHADD). Applying ten successive tactile stimuli to the anterior $(a)$ or posterior $(p)$ region of the L4 worms and counting their positive ( $a$, backward movement; $p$, forward movement) or negative ( $a$, forward movement; $p$, backward movement) reactions revealed in case of posteriorly stimulated wild type significant decreases in positive and increases in negative reactions under test conditions in comparison to the control condition. These effects were not observed in case of $n h r-69 \Delta$.

Effects of testosterone and ADDs on the reproduction rate of wild type and $n h r-69 \Delta$. As a previous study ${ }^{53}$ has shown negative effects of testosterone on the fecundity of C. elegans, with this effect increasing significantly during the long-term exposure over several generations, wild type (Fig. 2a-c) or $n h r-69 \Delta$ (Fig. 2d-f) were kept over three successive generations (F0, F1, F2) under control or test conditions (exposure to $5 \mu \mathrm{M}$ of testosterone, $\mathrm{ADD}, 7 \alpha-\mathrm{HADD}, 12 \beta-\mathrm{HADD}$, and $12 \beta-\mathrm{DHADD})$, with the F0 generation originating from worms still bred under the control condition.

Within each generation, the time-dependent increase in the number of offspring from individual worms was determined over 3-day periods. The number of offspring was consistently lower in $n h r-69 \Delta$ worms. The number of offspring determined over all three generations was negatively affected in wild type, but not in $n h r-69 \Delta$ by tes-

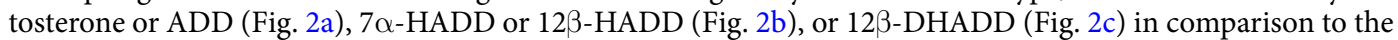
control condition. Additionally, there were intergenerational differences in reproduction rate between F0 or F1 and F2 in wild type and $n h r-69 \Delta$ in case of $7 \alpha-H A D D$ and $12 \beta-H A D D$ exposure (Fig. 2b,e).

Effects of testosterone and ADDs on the developmental speed of wild type and $n h r-69 \Delta$. The developmental speed of C. elegans wild type (Fig. 3a) or $n h r-69 \Delta$ (Fig. 3b) from egg to adult worm was assessed under control or test conditions (exposure to $5 \mu \mathrm{M}$ of testosterone, ADD, $7 \alpha-\mathrm{HADD}, 12 \beta-\mathrm{HADD}, 12 \beta-\mathrm{DHADD}$ ) by determining the percentage share of L1, L2, L3, and L4 larval stages and adult worms one, two, and three days after egg laying. Significant differences in developmental speed were detected on the third day. Wild type showed a significantly slower developmental speed than $n h r-69 \Delta$ as well as significant differences in developmental speed between different treatments (e.g. 12 $\beta$-HADD exposure vs. $12 \beta$-DHADD exposure or the control condition).

Effects of 7 $\alpha-H A D D$ on the transcriptome of wild type. To explore the genetic basis of the described effects of ADDs in a case study, transcriptome profiling by RNA-Seq was carried out on synchronized adult $C$. elegans wild type or $n h r-69$ that had developed from the L1 to the adult stage under control or test conditions 


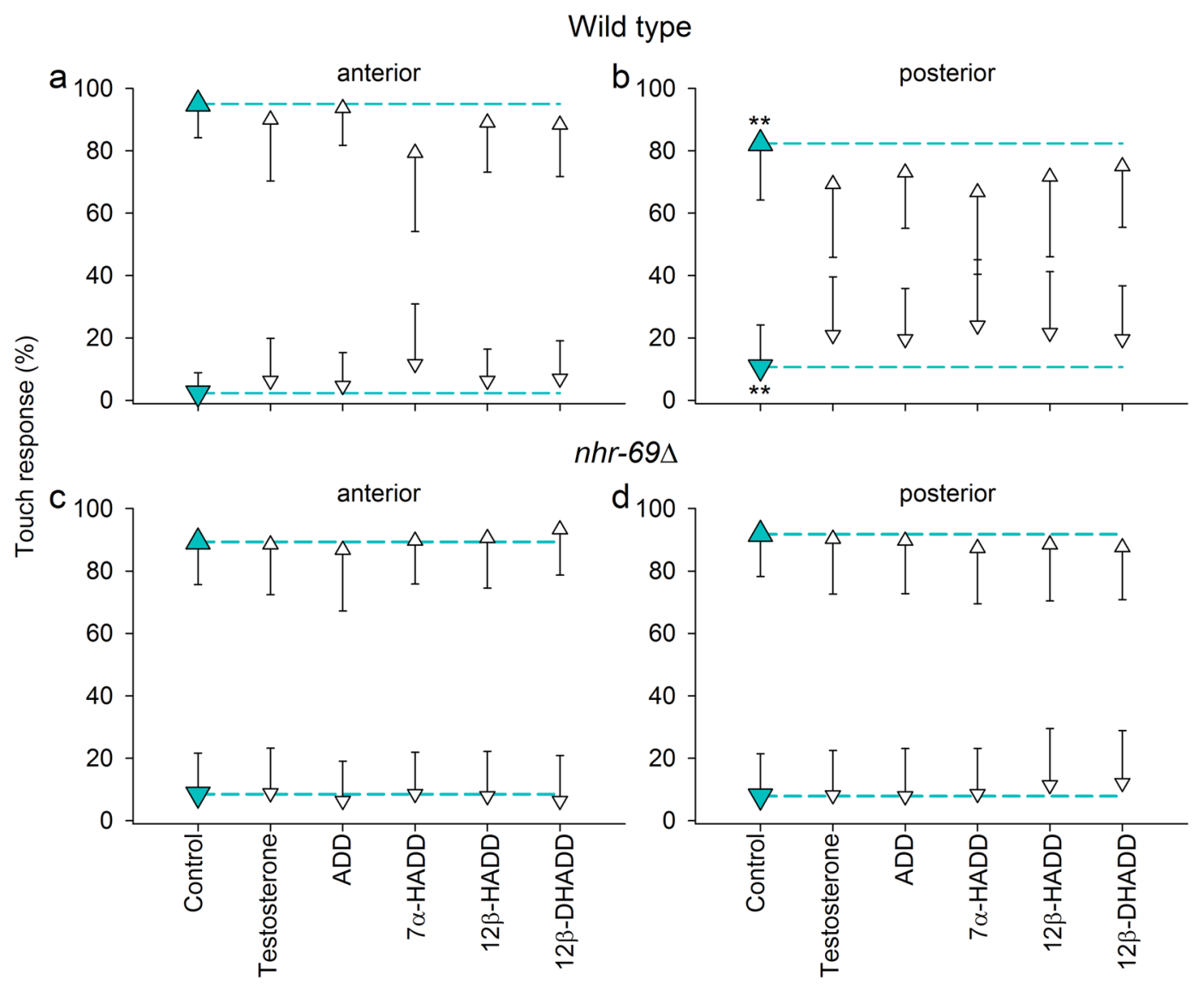

Figure 1. Effects of steroid compounds on the gentle touch response of wild type and $n h r-69 \Delta$. Positive (upturned triangles) or negative reactions (downturned triangles) of C. elegans (a,b) wild type or (c,d) $n h r-69 \Delta$ worms to successive tactile stimuli applied either to the $(\mathbf{a}, \mathbf{c})$ head (anterior) or $(\mathbf{b}, \mathbf{d})$ tail region (posterior) of L4 worms that had developed from egg to this larval stage under control (green symbols and lines) or five test conditions (exposures to testosterone, ADD, $7 \alpha$-HADD, $12 \beta$-HADD, or 12 $\beta$-DHADD) (mean \pm sd; per experimental condition, $n \geq 60$ different worms). Asterisks indicate significance levels ( $* * P<0.01$; two-way ANOVA and subsequent Student-Newman-Keuls analysis).

(exposure to $5 \mu \mathrm{M}$ of $7 \alpha-\mathrm{HADD}$ ). Within each of the ten used animal samples, more than 15,000 identified (i.e. with a WormBase identification number, WB GeneID) and expressed genes were detected, whose expression level was quantified using the FPKM method (see Material and Methods). Screening the differently regulated genes of the four different contrasts by the NOISeq method (see Material and Methods) revealed 1165 (WT_7 $\alpha$-HADD vs. WT_control), 3 ( $n h r-69 \Delta \_7 \alpha-H A D D$ vs. $n h r-69 \Delta$ _control), 5386 ( $n h r-69 \Delta$ _control vs. WT_control), and 4002 ( $n h r-69 \Delta \_7 \alpha-$ HADD vs. WT_ $7 \alpha-$ HADD) differentially expressed genes with a diverge probability of greater than or equal to 0.8 (abbreviated as DEGs). For analyzing differential gene regulation either for the greater number of genes with identical WB GeneID or the smaller number of DEGs, the mean expression intensities (averaged FPKM values) of corresponding genes or DEGs were plotted against each other (x-y plots) either in case of wild type (Fig. 4a,b; Supplemental Fig. S2a,b) or $n h r-69 \Delta$ (Fig. 4c,d; the only three DEGs were not graphically represented) under control and test conditions or for wild type and $n h r-69 \Delta$ under control (Fig. 4e,f; Supplemental Fig. S2c,d) or test (Fig. 4g,h; Supplemental Fig. S2e,f) conditions. As criteria for actually existing differences in gene regulation either distinct deviations from the 45-degree diagonal line in double linear plots (left graphs) or strong $\log _{2}$-fold differences in expression intensity in double $\log _{2}$ plots (right graphs) were chosen, with the two scale types chosen to emphasize genes with higher (double linear plots) or lower expression intensity ( $\operatorname{double} \log _{2}$ plots). The function of these gene groups was studied by gene ontology (GO) analyses (functional annotation chart; David Bioinformatics Resources 6.8). Most of these genes were functionally assignable.

The gene groups identified in the double linear plots (Fig. 4 and Supplemental Fig. S2, left graphs, red circles) commonly comprised genes or DEGs for translational processes, with annotation terms like ribosomal protein or translation (Supplemental Tables S1, S2). The same was valid for the hardly regulated genes of $n h r-69 \Delta$ under control and test conditions (Fig. 4c). Thus, the varying degree of deviation from the 45-degree diagonal line indicates differences in the regulation of genes or DEGs for translational processes. Upregulations of genes or DEGs seemed to increase in the following order: $n h r-69 \Delta$ under test conditions (Fig. 4c), wild type under control conditions (Fig. 4a; Supplemental Fig. S2a) or wild type in comparison to $n h r-69 \Delta$ under test conditions (Fig. 4g; Supplemental Fig. S2e), and wild type in comparison to $n h r-69 \Delta$ under control conditions (Fig. 4e; Supplemental 
a

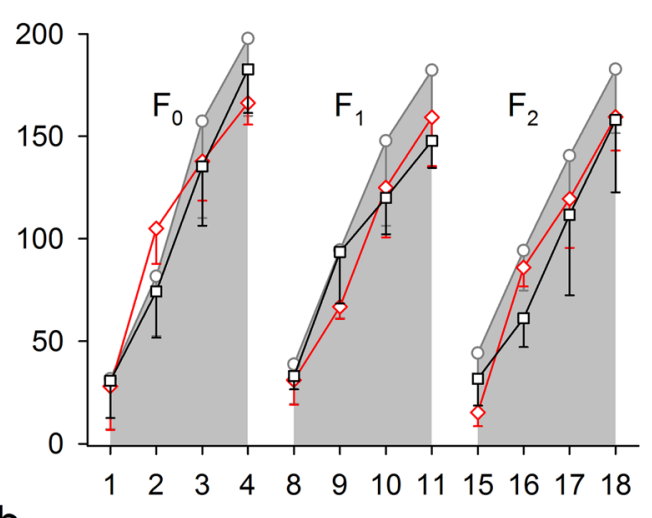

b
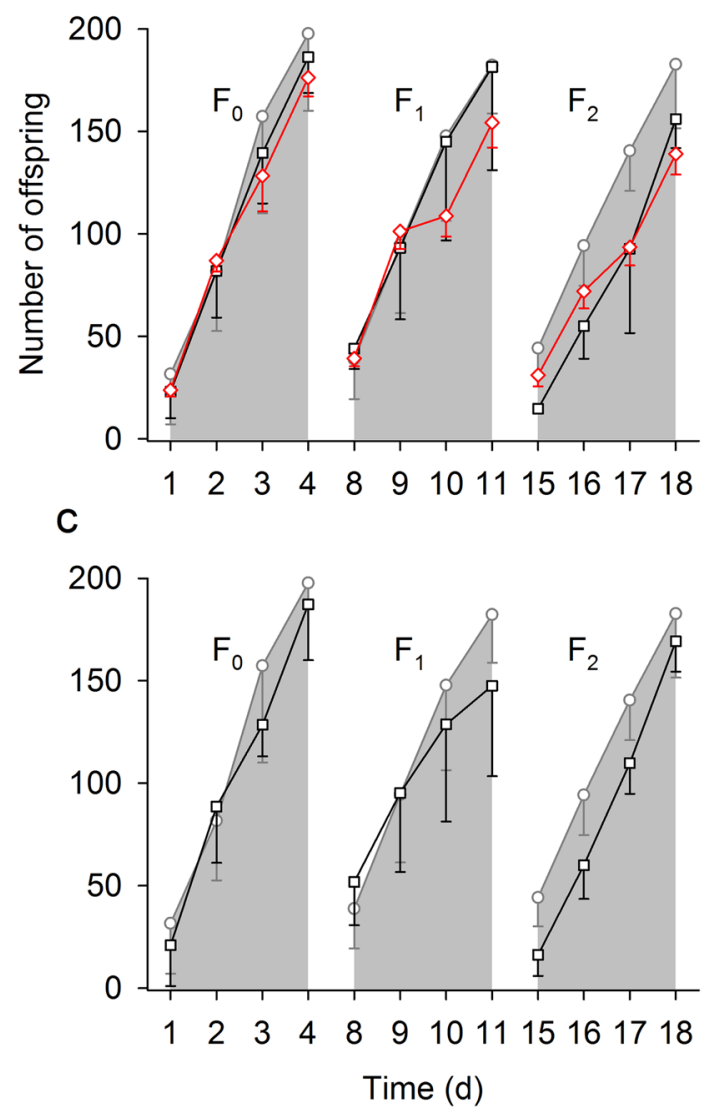

d

$n h r-69 \Delta$
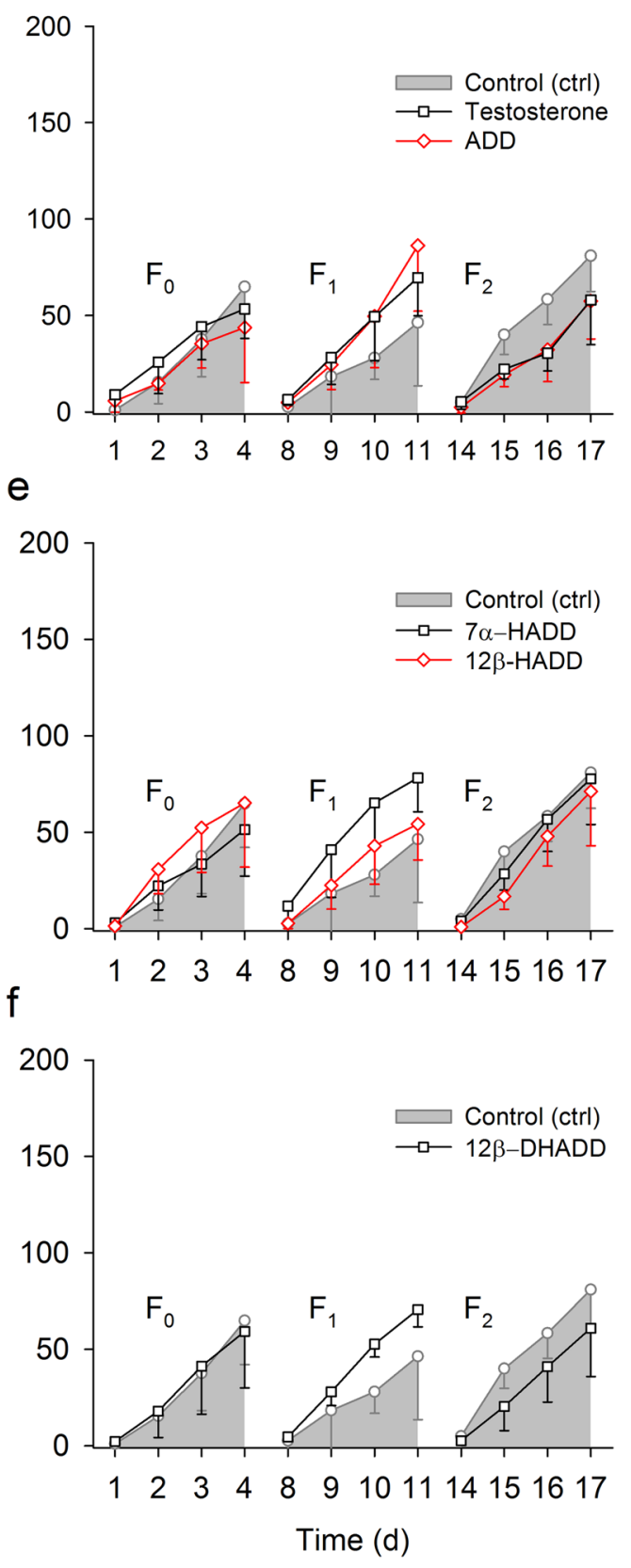

Figure 2. Effects of steroid compounds on the reproduction rate of wild type and $n h r-69 \Delta$. Time-dependent increases in the number of offspring of individual C. elegans worms determined over three successive generations (F0, F1, F2) and over 3-day periods each in (a-c) wild type or $(\mathbf{d}-\mathbf{f}) n h r-69 \Delta$ under control (grey symbols, lines, and areas) or five test conditions [exposures to (a,d) testosterone or ADD, (b,e) $7 \alpha$-HADD or

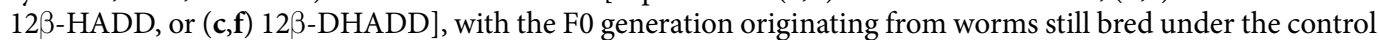

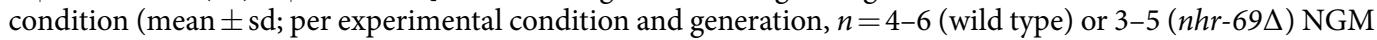
plates with one egg laying worm each). Three-way ANOva and subsequent Student-Newman-Keuls analysis (see Supplemental Table S3, which summarizes all statistical analyses and significances for this figure) revealed in wild type and in comparison to the control condition negative effects of (a) testosterone or ADD, (b) 7 $\alpha$-HADD

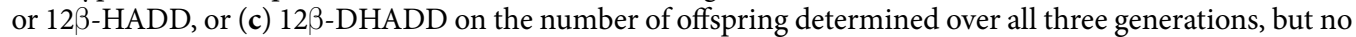
significant effects of these steroid compounds on the low number of offspring in $n h r-69 \Delta$.

Fig. S2c). Thus, gene expression for translational processes was higher in wild type than in $n h r-69 \Delta$, and the exposure to $7 \alpha-\mathrm{HADD}$ reduced this type of gene expression in wild type but affected it hardly (genes) or not (DEGs) in $n h r-69 \Delta$. 
Wild type (day 3)

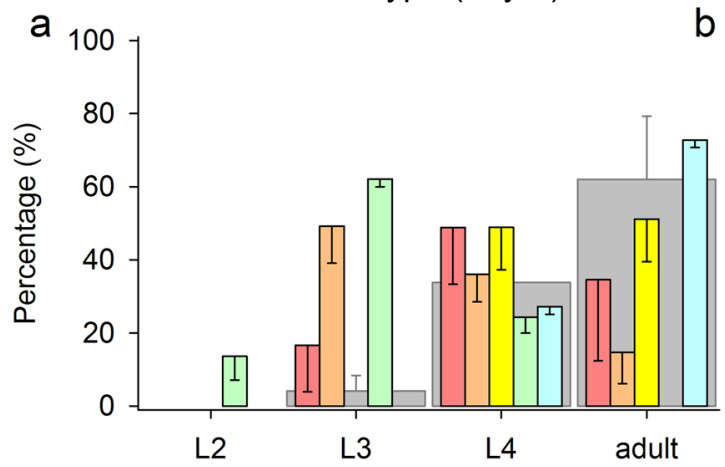

b

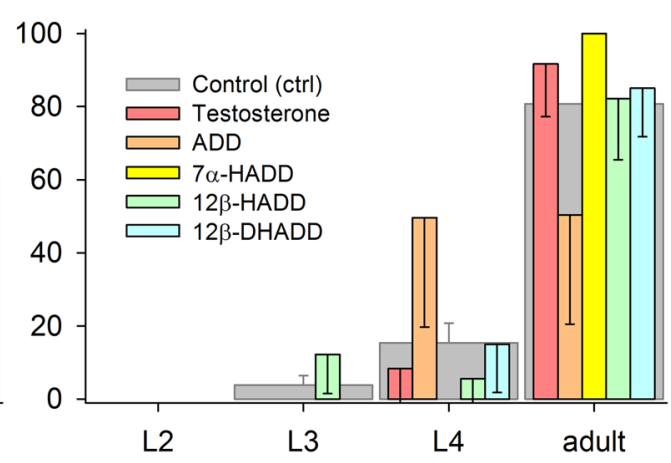

Figure 3. Effects of steroid compounds on the developmental speed of wild type and $n h r-69 \Delta$. The developmental speed of $C$. elegans (a) wild type or (b) $n h r-69 \Delta$ was assessed under control or five test conditions (exposures to testosterone, ADD, $7 \alpha-\mathrm{HADD}, 12 \beta-\mathrm{HADD}$, or $12 \beta-\mathrm{DHADD}$ ) by determining the percentage share of larval stages (L1-L4) and adult worms. Significant differences in developmental speed were detected three days after egg laying (mean \pm se; per experimental condition, $n=3-4$ NGM plates with one worm each, which was present only during egg laying). One-way ANOvA and subsequent Student-Newman-Keuls analysis revealed significant differences in developmental speed between (a) wild type and (b) $n h r-69 \Delta(P=0.01)$ and in (a) wild type generally between all six conditions $(P=0.013)$ and specifically between $12 \beta-\mathrm{HADD}$ and $12 \beta$-DHADD treatment $(P=0.018)$ or $12 \beta$-HADD treatment and control condition $(P=0.035)$, with an almost significant difference between $12 \beta$-DHADD and ADD treatment $(P=0.051)$. There were no significant differences between the different conditions in $n h r-69 \Delta$.

The groups of genes identified in the double $\log _{2}$ plots (Fig. 4, right graphs, green and red circles) comprised genes, which were frequently assigned to terms that are likely related to (i) steroid hormones (e.g., NHRs) (Supplemental Table S1, red background colour), (ii) G protein-coupled receptors (GPCRs) and sensory perception (e.g., serpentine receptors) (Supplemental Table S1, yellow background colour), (iii) innate immune response (e.g., C-type lectins) (Supplemental Table S1, green background colour), and (iv) phosphorylation/dephosphorylation (e.g., protein kinases) (Supplemental Table S1, blue background colour).

Thus, we screened the results from the Basic Local Alignment Search Tool (BLAST), which was applied on the RNA-Seq data by the Beijing Genomics Institute (BGI), for corresponding genes and detected numerous genes for hormonal functions (essentially genes for NHRs), serpentine receptors, and lectins or galectins. The mean expression intensities of these genes were then analysed in wild type or $n h r-69 \Delta$ under control and test conditions in a similar way as aforementioned (x-y double $\log _{2}$ plots; Fig. 4), with the difference that a distinction was now made between up- or downregulated genes and that gene enrichment analyses (chi-square tests) were carried out to identify deviating regulation, for which the gene-specific ratio between up- and downregulated genes (e.g., genes for hormonal functions) was significantly different from the contrast-specific ratio (e.g., wild type under control and test conditions). These analyses showed in case of genes for hormonal functions significant upregulations in wild type due to $7 \alpha-\mathrm{HADD}$ exposure (Fig. 5a) and significant upregulations in $n h r-69 \Delta$ in comparison to wild type under control (Fig. 5c) or test conditions (Fig. 5d). Deviating regulation was not detected in case of genes for serpentine receptors. Genes for lectins or galectins showed significant upregulations (in relation to the contrast-specific ratio) in wild type either under control conditions (Fig. 6a) or in comparison to $n h r-69 \Delta$ under control (Fig. 6c) or test (Fig. 6d) conditions.

The groups of DEGs identified in the double $\log _{2}$ plots (Supplemental Fig. S2, right graphs, green and red circles) comprised genes for quite different processes such as developmental (Supplemental Table S2, yellow background color) or nuclear processes including DNA damage and repair (Supplemental Table S2, blue background color). Genes for developmental processes seemed to be upregulated in wild type under test conditions or in comparison to $n h r-69 \Delta$ under control conditions. Genes for nuclear processes were found to be upregulated in wild type under test conditions and in both strains under control or test conditions.

CDC degradation in soil microcosms. The presented results with isolated steroids from bacterial bile acid degradation raised the question whether such effects could also be observed when natural habitats of nematodes are supplied with bile acids, which are degraded by the endogenous bacteria. This investigation would in particular be interesting if the extracellular accumulation of intermediates of bile acid degradation could also be detected in the pore water of soil microcosms.

As $7 \alpha$-HADD showed strong effects on the physiology of C. elegans, further investigations were focused on CDC as its precursor in bacterial degradation. For investigating whether CDC is degraded in soil, slurry experiments were conducted with soil collected near agriculturally used fields in the Münsterland region. In all experiments, $1 \mathrm{mM} \mathrm{CDC}$ was completely degraded within about one week (Fig. 7a,b). Especially after $2 \mathrm{~d}$, many intermediates were detectable, which were identified as 3-keto-CDC, $\Delta^{4}$-3-keto-CDC, $7 \alpha$-hydroxy-3-oxo-pre gna- $\Delta^{1,4}$-diene-carboxylate ( $7 \alpha-$ HOPDC) and the $\Delta^{4}$-monoene corresponding to $7 \alpha$-HOPDC (Fig. $7 \mathrm{c}$ ) by UV-spectroscopy and mass spectrometry as described earlier ${ }^{54}$ These steroid metabolites are also found in supernatants of laboratory cultures of bile acid degrading bacteria such as Pseudomonas stutzeri Chol ${ }^{11,54}$. 

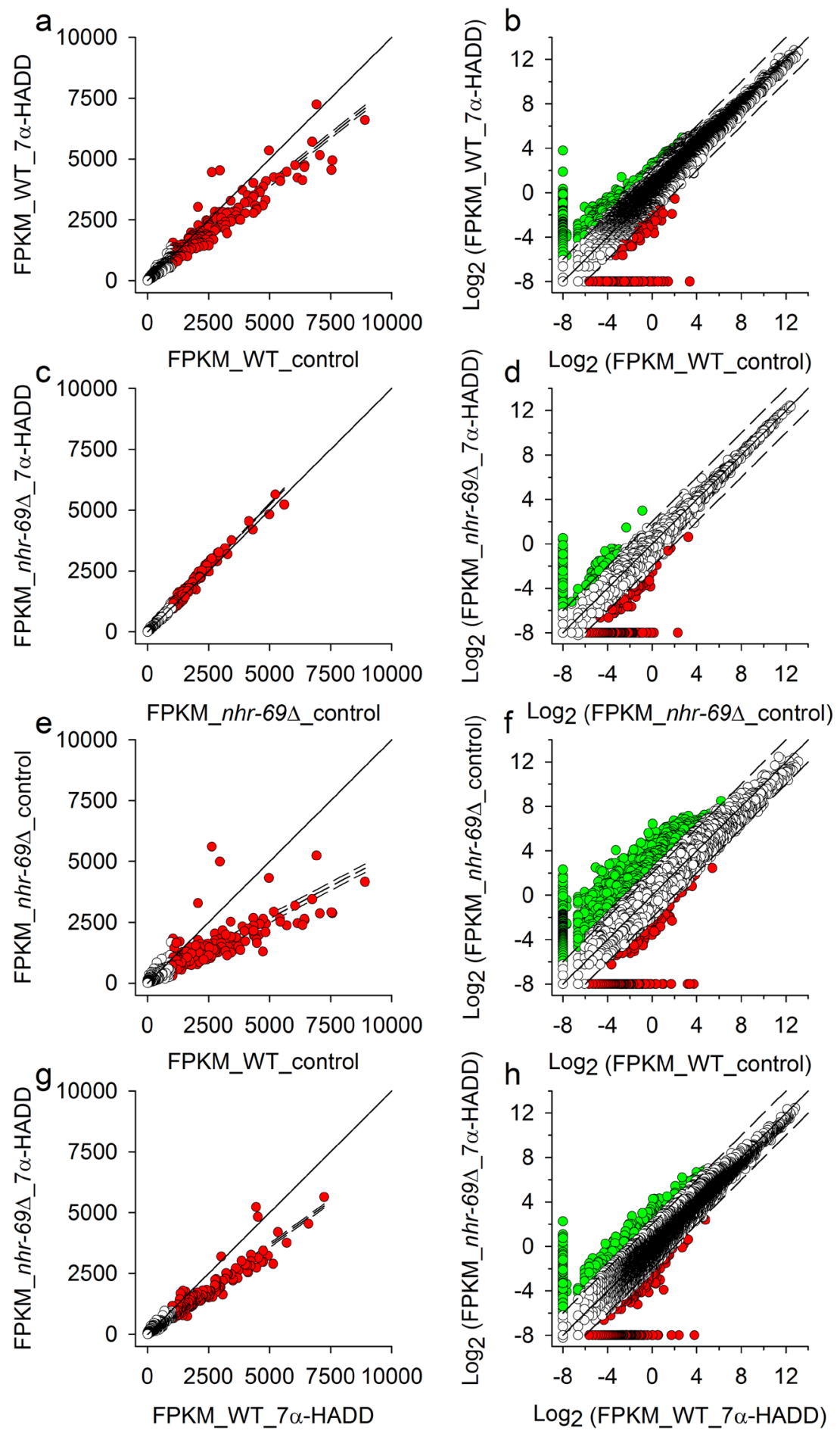

Figure 4. Gene expression intensities in wild type or $n h r-69 \Delta$ after breeding under control or test conditions. Transcriptome profiling was performed by RNA-Seq to determine gene expression intensities in synchronized adult C. elegans (a,b) wild type (WT) or (c,d) $n h r-69 \Delta$ that had developed from the L1 to the adult stage under control and test ( $7 \alpha-\mathrm{HADD}$ exposure) conditions. Additionally, the gene expression intensities of the two C. elegans strains are shown under $(\mathbf{e}, \mathbf{f})$ control or $(\mathbf{g}, \mathbf{h})$ test conditions [averaged FPKM values; per strain and experimental condition, $n$ : mostly 3 biological replicates (see Material and Methods)]. The $\mathrm{x}$-y plots show the expression intensities of all genes, which carried a WormBase identification number (WB GeneID), as double linear (left graphs) or double $\log _{2}$ (right graphs) plots (continuous lines mark the 45-degree diagonal lines) to emphasize genes with higher or lower expression intensity. Genes with a mean FPKM value higher than 1000 on the $x$-axis mostly deviated from the 45-degree diagonal line (left graphs, red circles and dashed linear regression and 99\% prediction lines). Genes with lower mean FPKM values and deviations from equal $\log _{2}$-fold expression intensity (45-degree diagonal lines) of lesser than -2 or greater than 2 between $\mathrm{x}$-axis and $\mathrm{y}$-axis (right graphs, green or red circles and dashed offsets of -2 and 2) were also functionally characterized by GO analyses (see Supplemental Table S1). 
Genes related to hormonal function (nuclear hormone receptors)
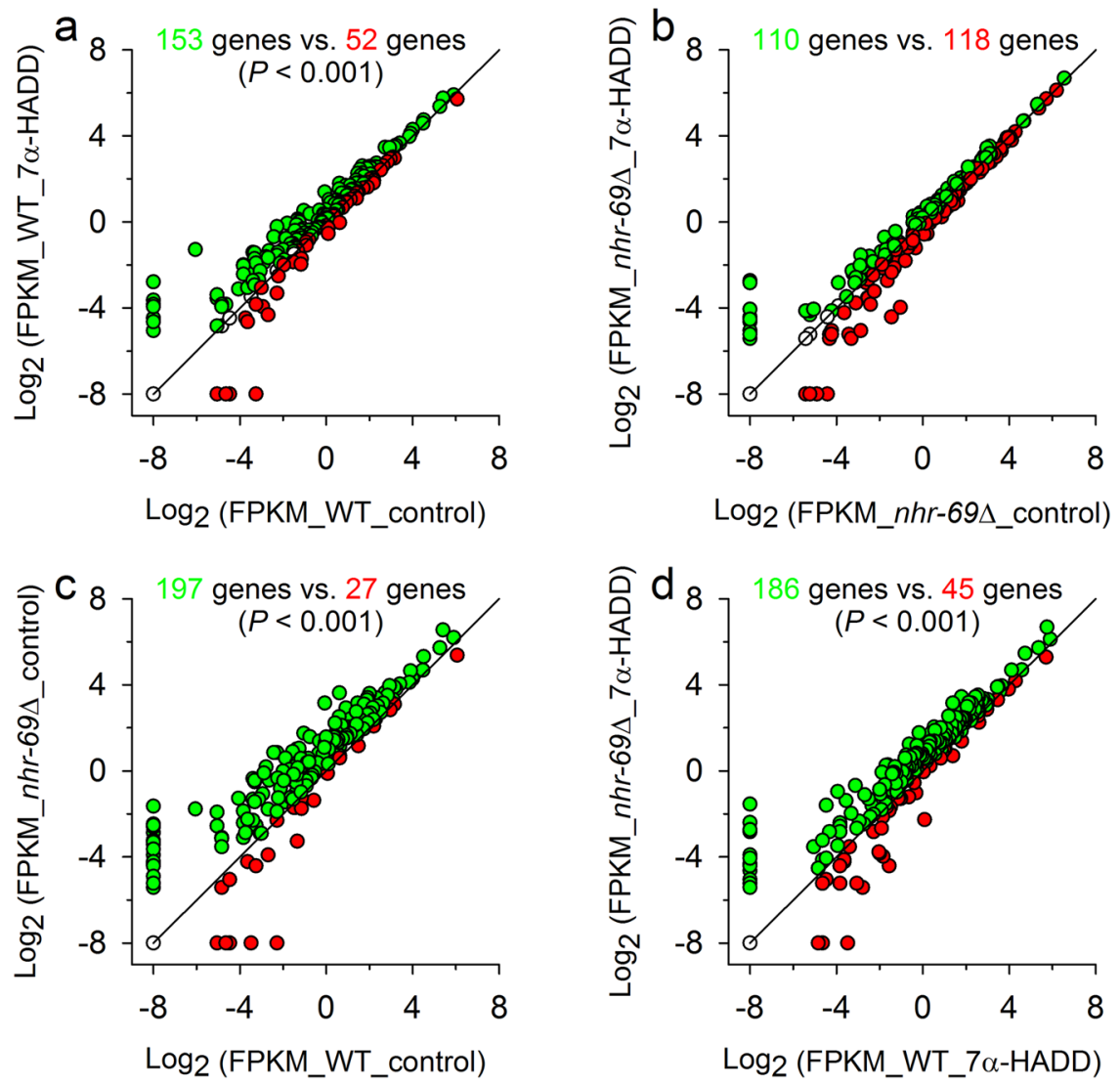

Figure 5. Expression intensities of genes related to hormonal function in wild type or $n h r-69 \Delta$ after breeding under control or test conditions. Double $\log _{2}$ plots of the expression intensities (mean FPKM values) of genes

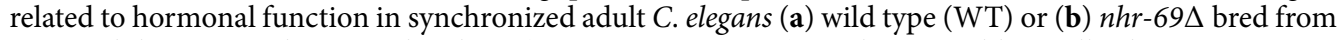
egg to adult worm under control and test ( $7 \alpha$-HADD exposure) conditions. Additionally, the gene expression intensities of the two C. elegans strains are shown under (c) control or (d) test conditions. Deviating regulation (i.e., up- or downregulated genes) is indicated by different symbol colours (green or red circles). The numbers of up- or downregulated genes are given in the corresponding colour, together with the significance level $(P$ values from chi-square analyses) in case of significantly deviating regulation (see text). Continuous lines mark the 45-degree diagonal lines.

CDC degradation in sand microcosms and effects on C. elegans. In a next step, it was tested whether the reproduction of $C$. elegans is affected by the presence of bile acid degrading bacteria. However, a reliable quantification of C. elegans individuals in soil microcosms was not possible. Nevertheless, the reproduction of $C$. elegans can be quantified in semi-natural sand microcosms with E. coli as food bacteria ${ }^{55}$. For enabling bacterial bile acid degradation, the model organism P. stutzeri Choll was additionally used here ${ }^{54}$.

In preliminary experiments on sand microcosms without worms but with $0.25 \mathrm{mM} \mathrm{CDC}$ for testing CDC degradation, a transient extracellular accumulation of 3-keto-CDC, $7 \alpha-\mathrm{HOPDC}, 7 \alpha$-HADD and the seco-steroid $7 \alpha$-dihydroxy-9,10-seco-androsta- $\Delta^{1,3,5}$-triene-9,17-dione ( $7 \alpha$-DHSTAD) was observed (Supplemental Fig. S3).

As C. elegans incubations should last several days, bile acid degradation after repeated additions of CDC was determined (Fig. 8). About $20 \mathrm{~h}$ after each addition of CDC, CDC was completely degraded. About $6 \mathrm{~h}$ after each addition of CDC, the intermediates described above were detected and after $20 \mathrm{~h}$, they were degraded. In the presence of E. coli OP50 ${ }_{\text {-ura }}$ at an optical density at $600 \mathrm{~nm}\left(\mathrm{OD}_{600}\right)$ of 0.147 , CDC was not degraded, but partially transformed to 7-keto-CDC (Supplemental Fig. S4). In order to test whether C. elegans has effects on CDC degradation, experiments were repeated with ten adult worms on each plate. In these preparations, CDC degradation took place as in the preparations without C. elegans (Supplemental Fig. S5).

Finally, the reproduction rate of adult C. elegans worms was quantified in sand microcosms (Fig. 9). The presence or absence of CDC without $P$. stutzeri Choll showed no significant effects on reproduction rate. The addition of $P$. stutzeri Choll to the already present food bacteria $\left(E\right.$. coli OP50 $\left.{ }_{\text {-ura }}\right)$ promoted the reproduction rate of C. elegans which, however, was reduced by the addition of CDC. 


\section{Genes for lectins/galectins}
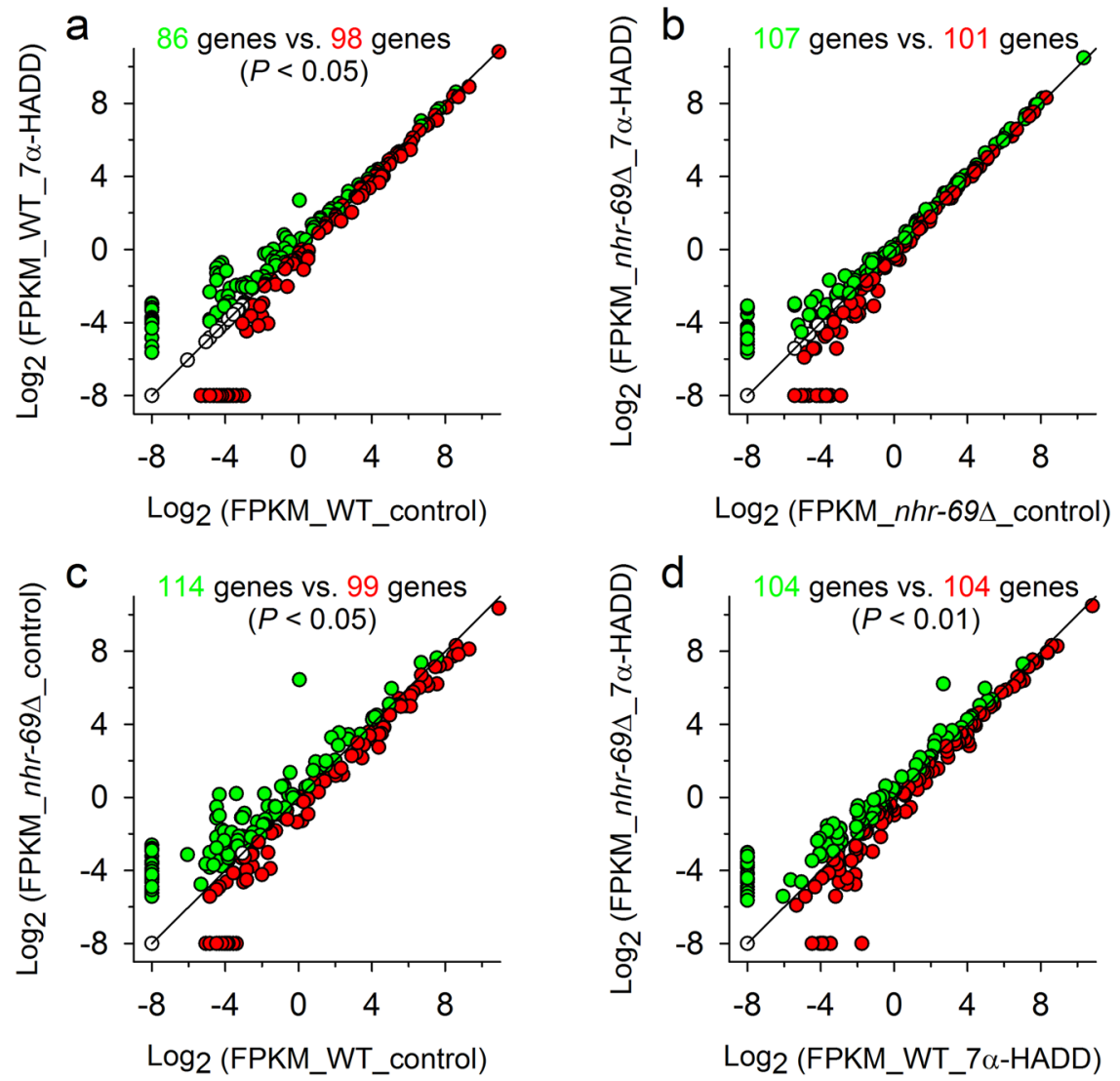

Figure 6. Expression intensities of genes for lectins or galectins in wild type or $n h r-69 \Delta$ after breeding under control or test conditions. Double $\log _{2}$ plots of the expression intensities (mean FPKM values) of genes for lectins or galectins in synchronized adult C. elegans (a) wild type (WT) or (b) $n h r-69 \Delta$ bred from egg to adult worm under control and test ( $7 \alpha-$ HADD exposure) conditions. Additionally, the gene expression intensities of the two C. elegans strains are shown under (c) control or (d) test conditions. Deviating regulation (i.e., up- or downregulated genes) is indicated by different symbol colours (green or red circles). The numbers of up- or downregulated genes are given in the corresponding colour, together with the significance level ( $P$ values from chi-square analyses) in case of significantly deviating regulation (see text). Continuous lines mark the 45-degree diagonal lines.

\section{Discussion}

This study aimed at an investigation of possible effects of ADDs, which are formed as intermediates of bile acid degradation by bacteria, on the nematode Caenorhabditis elegans. Three primarily unrelated observations initiated this study, namely: (1) all bile-acid degrading bacteria analysed so far release steroid intermediates during growth in laboratory cultures ${ }^{11}$, (2) bile-acid degrading bacteria are widespread and can readily be isolated from soil and freshwater environments ${ }^{11}$, and (3) high loads of manure lead to an unusual high input of bile acids on agricultural land ${ }^{2}$. As ADDs are among the most prominent steroid intermediates transiently released during bacterial bile acid degradation and are known to be hormonally active compounds, the degradation of bile acids might lead to endocrine effects on the soil fauna in manured soils. Our proof-of-concept study clearly showed that the tested ADDs, which were derived from four of the main bile acids occurring in manure (e.g., $7 \alpha-H A D D)$, have multiple effects on essential traits of C. elegans when applied in environmentally relevant concentrations. As these effects were absent in $n h r-69 \Delta$, it is possible that the tested steroids act on the NHR-69 receptor.

The developmental exposure of wild type to testosterone or ADDs negatively affected the posterior touch response, the reproduction rate in a transgenerational manner as well as the developmental speed of wild type but not of $n h r-69 \Delta$ worms. Regarding the gentle touch response, Gámez-Del-Estal et al..$^{48}$ have also reported fewer positive anterior or posterior touch responses in wild type after the exposure to testosterone (0.01-1 mM) during development. This effect lasted over four subsequent generations in the absence of the hormone. As the deacetylase inhibitor sodium butyrate or development over the Dauer stage eliminated the transgenerational effect of testosterone application, the authors suggested possible epigenetic effects of this hormone. BLAST searches showed the best matching of NHR-69 with the human androgen receptor ligand-binding domain, and effects of testosterone on the touch response were not detected in the outcrossed $(2 \times) n h r-69 \Delta$ mutant strain [nhr-69(ok1926) I], which together suggest that NHR-69 can bind testosterone. Mimoto et al. ${ }^{49}$ also 


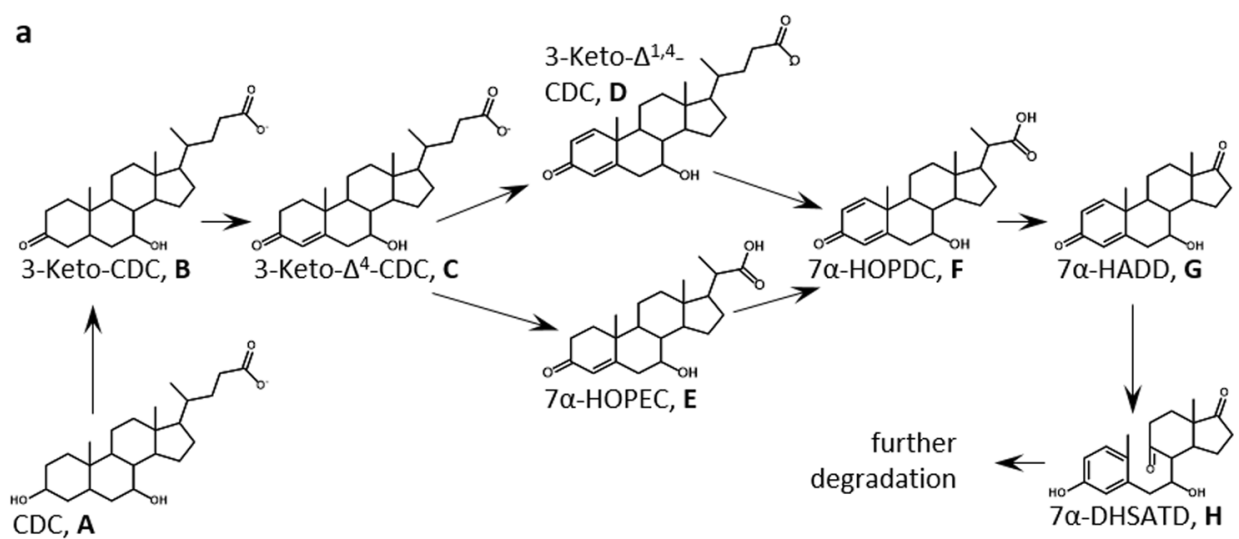

b

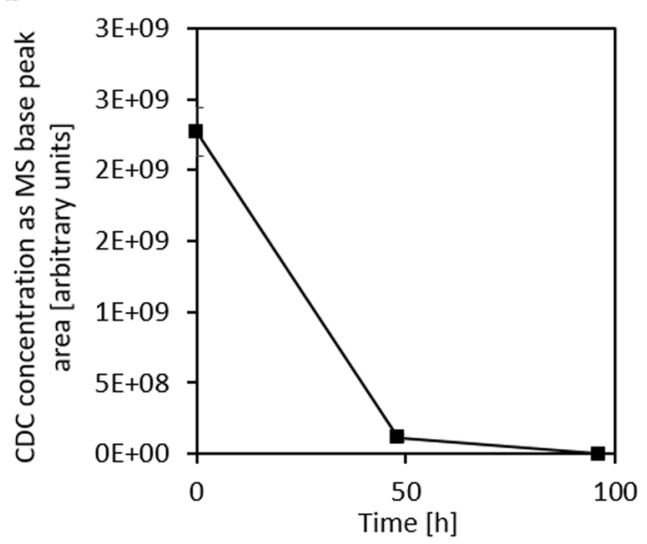

C

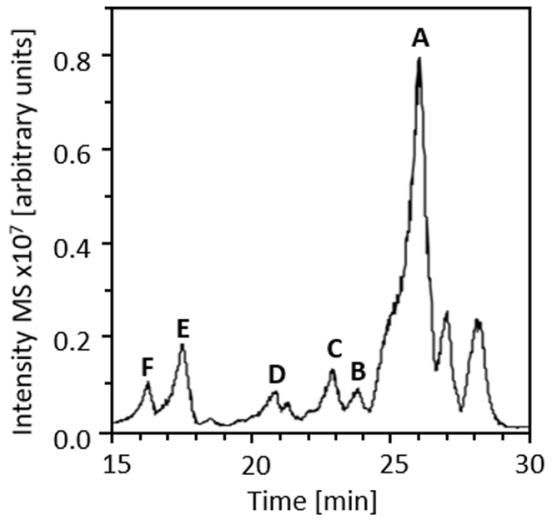

Figure 7. Fate of CDC in soil slurries. (a) Overview over CDC degradation by P. stutzeri Chol1. 7 $\alpha$-HOPDC: Hydroxy-3-oxo-pregna- $\Delta^{1,4}$-diene-carboxylate, $7 \alpha$-DHSATD: $7 \alpha$-Dihydroxy-9,10-seco-androsta- $\Delta^{1,3,5}$-triene9,17-dione, (b) Degradation of $1 \mathrm{mM} \mathrm{CDC}$ in soil slurry. CDC concentration was determined as base peak area of total ion counts in negative mode MS measurements. (mean $\pm \mathrm{sd}, n=3$ ). (c) MS base peak chromatogram of the extracted supernatant of a soil slurry incubated with $1 \mathrm{mM} \mathrm{CDC} \mathrm{for} \mathrm{about} 48 \mathrm{~h}$ and proposed structures of degradation intermediates. Samples were measured in negative MS mode; structure assignments are based molecular masses and UV absorption spectra.

demonstrated the capacity of NHR-69 to bind testosterone. As specific neural circuits are responsible for the gentle touch response of C. elegans ${ }^{56}$, testosterone may have affected the functionality of neuronal synapses via NHR-69-mediated gene expression ${ }^{48}$, which may also apply to the ADDs tested in the present study.

Regarding the reproduction rate, Tominaga et al. ${ }^{53}$ have also shown a reduced fecundity of wild type after a developmental exposure to $5 \mu \mathrm{M}$ of testosterone, with this effect increasing significantly during a long-term exposure over five generations. Thus, epigenetic effects may also contribute to the testosterone-mediated effects on reproduction rate (see above). The lower reproduction rate of $n h r-69 \Delta$ and the absent effects of the tested steroid compounds on the fecundity of this strain in the present study may have resulted from absent positive effects of NHR-69 on reproduction, mediated by a yet unknown steroid hormone. The tested steroids, however, showed negative effects on the reproduction of wild type, possibly due to a competitive inhibition of the NHR-69 receptor.

The reason for the negative effects of the tested steroid compounds on the developmental speed of wild type may also be a competitive inhibition of NHR-69. As the developmental speed of $n h r-69 \Delta$, however, was not significantly affected by the tested steroid compounds, the mutant may have involved other NHRs and steroid hormones in the determination of developmental speed, which possibly compensated for the missing NHR-69 receptor.

Thus, the tested steroid compounds may have negatively affected the NHR-69 receptor, which seems to be involved in reproduction and the gentle touch response but is obviously not obligatory in the determination of developmental speed.

Transcriptome profiling of the effects of $7 \alpha-H A D D$ on C. elegans wildtype and $n h r-69 \Delta$ supported these findings, as significant effects on gene expression for protein biosynthesis, hormone receptors, and proteins involved in the innate immune response were detected.

Gene expression for protein biosynthesis was higher in wild type than in $n h r-69 \Delta$, and it decreased in wild type but remained almost unaffected in $n h r-69 \Delta$ upon the exposure to $7 \alpha-H A D D$. An upregulated gene expression for protein biosynthesis indicates increasing investments in the translational machinery, with the aim of elevating the rate of protein biosynthesis. These proteins are required, for instance, for reproductive processes. Thus, 

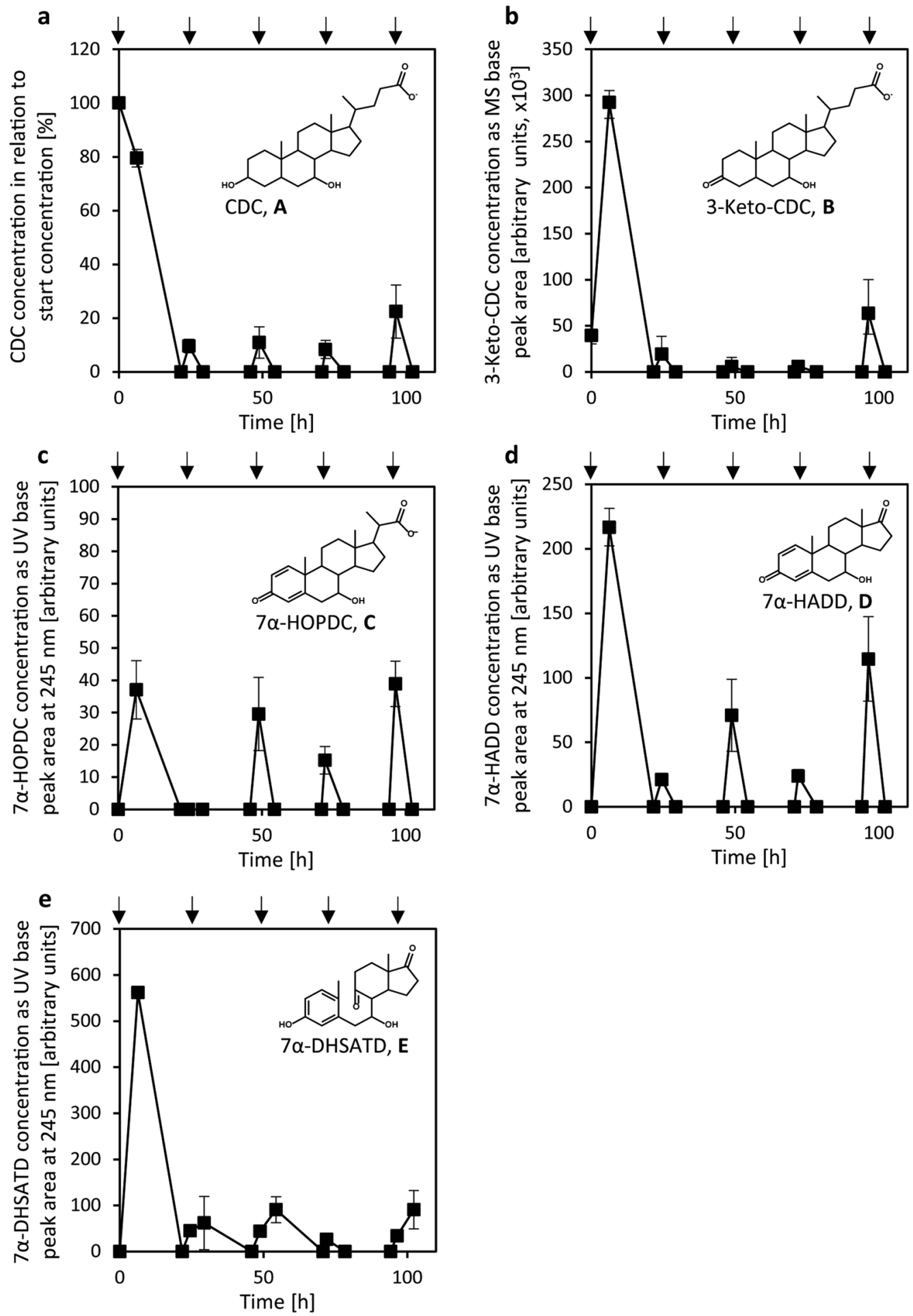

Figure 8. CDC degradation by P. stutzeri Choll in sand microcosms containing E. coli OP50 ${ }_{\text {-ura }}$ but not $C$. elegans. Degradation kinetics of CDC (a), 3-keto-CDC (b), $7 \alpha-H O P D C ~(\mathbf{c}), 7 \alpha-H A D D(\mathbf{d})$ and $7 \alpha-D H S A T D$ (e). Arrows indicate the addition of fresh suspensions of both bacteria and $0.25 \mathrm{mM} \mathrm{CDC}$. For each sample, the content of one sand microcosm was sacrificed and analysed by LC-MS. CDC concentration was determined as base peak area of total ion counts in negative mode in relation to the start concentration. Concentration of 3-keto-CDC was determined as base peak area of total ion counts in negative mode MS measurements. Concentration of $7 \alpha$-HADD and $7 \alpha$-HOPDC were determined as base peak areas in UV chromatograms at a wavelength of $245 \mathrm{~nm}$ and $7 \alpha$-DHSATD at a wavelength of $280 \mathrm{~nm}$. (mean $\pm \mathrm{sd}, n=3$ ). 


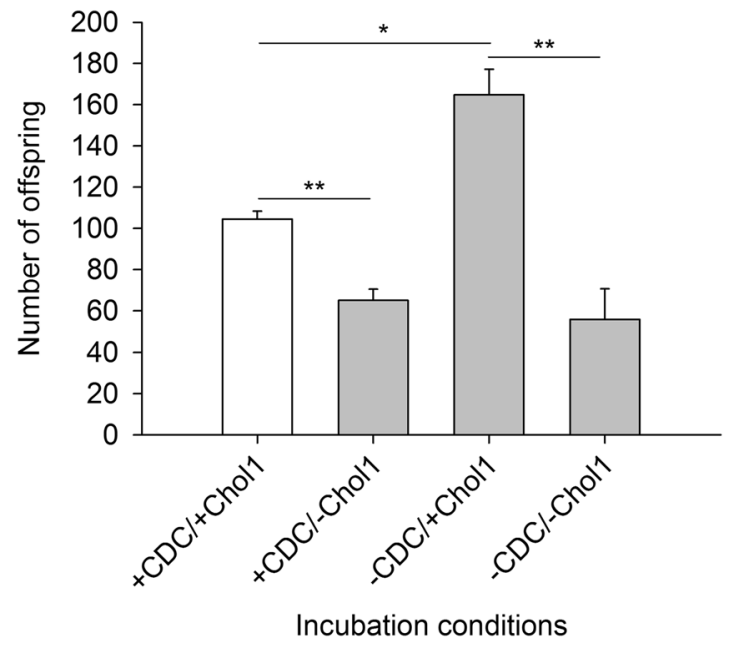

Figure 9. Steroid compounds from CDC degradation by P. stutzeri Choll reduced the reproduction rate of wild type. Number of offspring (normalized values; see Material and Methods) of adult C. elegans worms after four days of incubation with $(+)$ or without $(-)$ CDC or P. stutzeri Choll (mean \pm se; per experimental condition, $n=3-4$ biological replicates, and per biological replicate, $N=11$ petri dishes, with each petri dish containing one egg laying worm within a semi-natural medium). Asterisks indicate significance levels $\left({ }^{*} P<0.05\right.$, $* * P<0.01 ;$ t-test $)$

the higher reproduction rate and upregulated gene expression for protein biosynthesis in wild type in comparison to $n h r-69 \Delta$ as well as the lower reproduction rate and downregulated gene expression for protein biosynthesis in wild type upon the exposure to $7 \alpha$-HADD are likely related to each other. The absent effects of $7 \alpha-\mathrm{HADD}$ on the reproduction rate of $n h r-69 \Delta$ and the hardly present effects of this steroid compound on gene expression for protein biosynthesis in the mutant strain also match this potential relation.

Genes for hormonal functions (mostly for NHRs) were upregulated in $n h r-69 \Delta$ in comparison to wild type and upregulated in wild type upon the exposure to $7 \alpha$-HADD. The upregulation of these genes in $n h r-69 \Delta$ in comparison to wild type or in $7 \alpha$-HADD-exposed wild type may reflect a compensatory mechanism for a missing or blocked NHR-69 receptor by an intensified expression of other NHRs, which are hardly or not affected by the tested steroid compound.

C-type lectins are secreted antimicrobials, and their genes are targets of the p38/PMK-1 mitogen-activated protein kinase (MAPK) pathway ${ }^{57,58}$. Genes for lectins or galectins were downregulated in $n h r-69 \Delta$ in comparison to wild type and downregulated in wild type under test conditions. These findings indicate a suppression of the p38/PMK-1 MAPK pathway followed by a downregulated gene expression for lectins and galectins in case of a missing or blocked NHR-69 receptor. Thus, negative effects of an exposure to $7 \alpha-H A D D$ on the innate immune response of wild type are possible.

Analysing specifically the expression of DEGs also showed the already discussed effects of $7 \alpha-H A D D$ and/or strain on gene expression for protein biosynthesis (see above). Furthermore, DEGs for developmental processes seemed to be upregulated in wild type in comparison to $n h r-69 \Delta$ under control conditions. However, the expression of these DEGs and DEGs for nuclear processes was evidently also higher in $7 \alpha$-HADD-exposed wild type, which indicates effects of this steroid compound on still unclarified developmental processes. Most interestingly, differential gene expression was almost absent in $7 \alpha$-HADD-exposed $n h r-69 \Delta$ (i.e. 3 DEGs), which indirectly points to effects of this steroid compound on the NHR-69 receptor in wild type.

In soil and sand microcosms, CDC was readily degraded by natural microflora as well as by a model bacterium, which led to the transient release of degradation intermediates in both cases. Thus, an extracellular accumulation is not restricted to laboratory liquid cultures but occurs also during bile acid degradation in semi-solid environments. The reason for the transient extracellular accumulation of intermediates of bile acid degradation is still unknown. As bile acids and also part of their degradation intermediates are toxic to bacterial cells, it is likely related to the prevention of toxic effects ${ }^{12,59,60}$. Active export of bile acids via efflux pumps is well-known from gastrointestinal pathogens such as Vibrio cholerae ${ }^{61}$, which do not use bile acids for growth. Regarding steroid transport processes in bile acid degrading bacteria, respective mechanisms are only known so far in Gram-positive bile acid degrading bacteria of the genus Rhodococcus ${ }^{24}$. For Gram-negative Proteobacteria from which most of bile acid degrading bacteria originate, nothing has been published about steroid transport processes. ADDs were not detectable in the soil microcosms, which might be due to a strong adsorption of the relatively hydrophobic ADDs to soil particles, which has already been described for estradiol ${ }^{62,63}$. Nevertheless, ADDs may still be bioavailable to the nematodes. In the generally less hydrophobic sand microcosms, in contrast, an extracellular accumulation of $7 \alpha$-HADD was observed at concentrations sufficient for causing effects in C. elegans.

In sand microcosms, the reproduction rate of worms was very variable and low with E. coli OP50 ${ }_{\text {-ura }}$ as single food bacterium The presence of $P$. stutzeri Chol1 without CDC caused a higher number of offspring, which might be explained by the low quality of the standard food bacterium E. coli OP50 $0_{\text {-ura }}$, as a previous study has already reported that the addition of little amounts of other bacterial species to E. coli can promote the development and 
reproduction of C. elegans ${ }^{64}$. The presence of $P$. stutzeri Choll with CDC, however, evidently reduced the number of offspring probably due to the negative effects of degradation products of CDC produced by P. stutzeri Choll on C. elegans.

Besides ADDs, many other steroid degradation intermediates accumulated in sand microcosms, among them $\Delta^{1,4}$-3-keto bile acid derivatives with a full $C_{5}$-side chain as well as with a shortened $C_{3}$-side chain. These compounds resemble DAs with known effects on C. elegans ${ }^{65}$. Additionally, 9,10-seco-steroids, which are also known to have biological activities ${ }^{66}$, were formed. Therefore, the impact of CDC degradation might not be restricted to ADDs and, thus, might have contributed to the higher variability of the reproduction rate of C. elegans in the sand microcosms.

In natural habitats, the diversity of bile acids and their bacterial degradation intermediates is certainly even larger. Apart from the well-described $\Delta^{1,4}-3$-keto-pathway ${ }^{15,16,67,68}$, there is also an alternative pathway for initiating bile acid degradation that proceeds via $\Delta^{4,6}$-3-keto intermediates, which also transiently accumulate outside the cells ${ }^{69,70}$. In this respect, it has been shown that cross-feeding between bacteria using these different pathways may result in dead-end intermediates ${ }^{11}$. Furthermore, anaerobic steroid degradation with nitrate as electron acceptor can give rise to further steroid degradation intermediates ${ }^{71,72}$ and would be plausible to occur in oxygen-depleted zones in manured soils. In conclusion, our study calls attention to potentially harmful effects on the mesofauna caused by the bacterial transformation of bile acids in habitats with a high impact of manure. The accumulation of ADDs can also arise from the degradation of sterols, which make up a higher fraction of sterols in manure ${ }^{2,16}$. In this respect, bacterial steroid transformation may be a so far overlooked factor contributing to the decreasing biodiversity in agricultural environments ${ }^{73-75}$. Experiments for investigating bacterial bile acid degradation under in situ conditions as well as specific feeding experiments are on the way in our laboratory.

\section{Material and Methods}

Cultivation of bacteria. Escherichia coli OP50 $0_{\text {-ura }}$ was obtained from the Caenorhabditis Genetics Center (CGC; https://cgc.umn.edu/) and cultivated in LB medium (1\% tryptone, $0.5 \%$ yeast extract, $1 \% \mathrm{NaCl})^{76}$ or OP50 medium ( $2 \%$ peptone, $0.5 \% \mathrm{NaCl}, 0.001 \%$ uracil; $\mathrm{pH} 7.4$ ). Pseudomonas stutzeri Choll was cultivated under aerobic and anaerobic conditions in the phosphate-buffered mineral medium MMChol with $1 \mathrm{mM}$ of bile acids as carbon source ${ }^{12}$. Bacterial growth was monitored by measuring the $\mathrm{OD}_{600}$ with a spectrophotometer. For sand microcosms, $5 \mathrm{ml}$ of E. coli OP50 ${ }_{\text {-ura }}$ or P. stutzeri Choll cultures were harvested either in the late exponential or stationary growth phase by centrifugation $\left(8,000 \times \mathrm{g}, 3 \mathrm{~min}, 20^{\circ} \mathrm{C}\right)$ or after supplying $20 \%(\mathrm{v} / \mathrm{v})$ fresh LB or $1 \mathrm{mM}$ $\mathrm{CDC}$ to the cultures, respectively, and $1 \mathrm{~h}$ of further incubation. The cells were then washed and resuspended in MMChol without carbon source. New cell suspensions for sand experiments were prepared daily.

Cultivation of worms. The N2 Bristol variety of C. elegans (wild type, WT) and the deletion mutant $n h r-$ 69(ok1926) I ( $n h r-69 \Delta)$ were obtained from the CGC (https://cgc.umn.edu/). Worm cultures were maintained at $20^{\circ} \mathrm{C}$ on nematode growth medium (NGM) plates with E. coli OP50 -ura in OP50 medium $\left(\mathrm{OD}_{600}=1\right)$ as the food source $^{77}$. During experiments, the NGM plates contained the minimum amount of cholesterol that supports $C$. elegans growth $(0.5 \mu \mathrm{M} \text { of cholesterol })^{53}$. Control plates contained no further steroid compounds, whereas test plates contained $5 \mu \mathrm{M}$ of either testosterone, ADD, $7 \alpha$-HADD, $12 \beta$-HADD, or 12 $\beta$-DHADD.

Preparation of steroid compounds. Cholic acid ( $\geq 99 \%)$ from ox or sheep bile, deoxycholic acid ( $\geq 97 \%)$, lithocholic acid ( $\geq 98 \%$ ), and testosterone were purchased from Sigma-Aldrich (St. Louis, MO, USA). CDC $(\geq 98 \%)$ was purchased from Carl Roth $\mathrm{GmbH}+\mathrm{Co}$. KG (Karlsruhe, Germany), and ADD was purchased from Tokyo Chemical Industry UK Ltd. (Oxford, United Kingdom). For the preparation of 7 $\alpha$-HADD, 12 $\beta$-HADD or $12 \beta$-DHADD, P. stutzeri Choll was grown under anoxic conditions, with $2 \mathrm{mM}$ of deoxycholic acid, CDC or cholic acid as carbon source, respectively, as described ${ }^{12,78}$. All three ADDs were purified by organic extraction with dichloromethane ${ }^{78}$. The purity of steroid compounds was assessed by chromatography coupled to mass spectrometry and concentrations were determined photometrically ${ }^{78}$. For preparing stock solutions, testosterone and ADD were diluted in 100\% ethanol, $7 \alpha-$ HADD and $12 \beta-$ HADD in $70 \%$ ethanol, and $12 \beta$-DHADD in 50\% ethanol. Cholic acid and CDC were diluted in MilliQ pure water (Merck, Darmstadt, Germany).

LC-MS analysis. Steroid compounds and culture supernatants were analysed by liquid chromatography coupled to mass spectrometry (LC-MS) using a Dionex Ultimate 3000 LC system with a UV/visible light diode array detector (ThermoFisher Scientific; Waltham, MA, U.S.A.), and an ion trap mass spectrometer (Amazon speed; Bruker, Bremen, Germany) with an electro-spray ion source (ESI) as described previously ${ }^{70}$. For the evaluation of measurements, MS- or UV-base peak chromatograms or extracted ion chromatograms with defined mass ranges were used as indicated. For analysing the degradation of CDC and the accumulation of intermediates in sand, samples were centrifuged at $>16,000 \times g$ for $5 \mathrm{~min}$ at room temperature, before the supernatants were used for LC-MS analyses. For analysing the degradation of CDC and the accumulation of intermediates in the presence of C. elegans, samples were centrifuged as described, stored at $-20^{\circ} \mathrm{C}$, acidified $(\mathrm{pH} 1-2)$, cleaned from hydrophilic contaminants by organic extraction with ethyl acetate, and dissolved in methanol. Samples from soil experiments were also cleaned by organic extraction prior to the analysis by HPLC-MS. For that, $200 \mu \mathrm{l}$ of samples were acidified with $30 \mu \mathrm{l}$ of $1 \mathrm{M}$ of $\mathrm{HCl}(\mathrm{pH} \mathrm{1-2)}$ and extracted with $600 \mu \mathrm{l}$ of ethyl acetate. Ethyl acetate was dried off, and the samples were dissolved in $150 \mu \mathrm{l}$ of ethanol. All extracted samples were then analysed by LC-MS.

Gentle touch response assay. Single adult WT or $n h r-69 \Delta$ worms were allowed to lay eggs for $4 \mathrm{~h}$ at $20^{\circ} \mathrm{C}$ on test and control NGM plates, before the adult worms were picked off these plates. After developing from egg to the late $\mathrm{L} 4$ larval stage at $16^{\circ} \mathrm{C}$, with E. coli OP50 ${ }_{\text {-ura }}$ in OP50 medium as the food source, the gentle touch response of the L 4 worms was tested. The worms were slightly touched ten times just behind the pharynx 
(anterior, $a$ ) or before the anus (posterior, $p$ ) using an eyebrow mounted on a glass pipette. Positive ( $a$, backward movement; $p$, forward movement), negative ( $a$, forward movement; $p$, backward movement), or ambiguous reactions were scored ${ }^{56,79}$.

Fecundity assay. Single L4 worms of WT or $n h r-69 \Delta$ were transferred to test and control NGM plates with E. coli OP50 $0_{\text {-ura }}$ in OP50 medium as the food source $\left(\mathrm{T}=16^{\circ} \mathrm{C}\right)$. The offspring of these worms (including the eggs) was counted every day over 3-day periods (F0 generation) and kept under these conditions for further breeding. Single L4 worms of WT or $n h r-69 \Delta$ from the F0 generation were then transferred to new test or control plates, and the offspring was again counted every day over 3-day periods (F1 generation). The same procedure was applied to determine the offspring of single L4 worms of WT or $n h r-69 \Delta$ from the F1 generation (F2 generation).

Development assay. Single adult WT or $n h r-69 \Delta$ worms were allowed to lay eggs for 4 hours at $20^{\circ} \mathrm{C}$ on test and control NGM plates, before the adult worms were picked off these plates. The developmental speed from egg to adult worm at $20^{\circ} \mathrm{C}$, with E. coli OP50 -ura in OP50 medium as the food source, was determined by counting the number of L1, L2, L3, L4 and adult worms after 1, 2, and 3 days.

Transcriptome profiling. Synchronized ${ }^{77} \mathrm{~L} 1$ worms of WT or $n h r-69 \Delta$ developed to the adult stage on control or test (exposure to $5 \mu \mathrm{M}$ of $7 \alpha-\mathrm{HADD}$ ) NGM plates with E. coli OP50 -ura in OP50 medium as the food source $\left(\mathrm{T}=16^{\circ} \mathrm{C}\right)$. Then, worms were washed from the plates and cleaned two times using purified water to minimize the number of bacteria. The worms from five NGM plates per strain and experimental condition were combined to one animal sample, and three animal samples per strain and experimental condition (i.e., 12 animal samples in total) were further prepared for transcriptome profiling by RNA-Seq as described ${ }^{80,81}$. RNA samples were sent to the BGI for RNA-Seq analysis. Using Illumina HiSeq2000 technology, the RNA samples were sequenced with a minimum of 10 mega reads per sample and a sequencing quality of more than $98 \%$ clean reads. Sequences were mapped to WormBase release WS257. Expression intensities of genes were calculated (see below) using the FPKM method (fragments per kilobase of exon per million fragments mapped) to normalize for sequencing depth and gene length ${ }^{82}$, which can be directly used for comparing differences in gene expression between samples. In case of WT under control or test conditions, the data from one animal sample each differed significantly from the two others regarding the expression intensity of corresponding genes, and mean expression intensities were calculated here using the data from only two animal samples. In case of $n h r-69 \Delta$, however, the data from all three animal samples per experimental condition were useable for the calculation of mean expression intensities. Screening genes with differences in mean expression intensity in wild type or $n h r-69 \Delta$ between control and test conditions or between both strains under control or test conditions by the NOISeq method ${ }^{83}$ revealed differentially expressed genes with a diverge probability of greater than or equal to 0.8 (termed DEGs). David Bioinformatics Resources 6.8 (functional annotation chart) was used for GO analyses.

Bile acid degradation in soil microcosms. Soil microcosms were prepared by mixing $1 \mathrm{~g}$ of soil collected from sites close to various agriculturally used fields in the Münsterland region with $1 \mathrm{ml}$ of CDC solution ( $1 \mathrm{mM}$; $\mathrm{pH} 8$, set with $\mathrm{NaOH}$ ) in a $2 \mathrm{ml}$ plastic tube (Sarstedt, Nümbrecht, Germany). For each microcosm experiment, 30-60 plastic tubes were prepared in parallel and incubated at room temperature. At several time points, three tubes were used for sampling by centrifugation at $>16,000 \times g$ for $5 \mathrm{~min}$ at room temperature. Supernatants were stored at $-20^{\circ} \mathrm{C}$ until extraction for LC-MS measurements.

Bile acid degradation in sand microcosms. Quartz sand (Siligran, washed; Ø: 0.7-1.2 mm) was obtained from Euroquarz (Dorsten, Germany) and sterilized by baking at $180^{\circ} \mathrm{C}$ for at least $6 \mathrm{~h}$. Sand microcosms were prepared by filling $3 \mathrm{~g}$ or $25 \mathrm{~g}$ of sand into petri dishes $(\varnothing: 3.5 \mathrm{~cm}$ or $9.2 \mathrm{~cm}$, respectively). To obtain cell suspensions for the sand microcosms, E. coli OP50 ${ }_{\text {-ura }}$ and P. stutzeri Chol1 were cultivated overnight. Cell suspensions were prepared from re-fed cultures, containing E. coli OP50 ${ }_{\text {-ura }}$ at an $\mathrm{OD}_{600}$ of 0.133 and P. stutzeri Choll at an $\mathrm{OD}_{600}$ of 0.013 or only E. coli OP50 ${ }_{\text {-ura }}$ at an $\mathrm{OD}_{600}$ of $0.147 .0 .25 \mathrm{mM}, 0.5 \mathrm{mM}$ or $1 \mathrm{mM}$ of CDC was added to the cell suspensions as indicated. Petri dishes with a diameter of $9.2 \mathrm{~cm}$ or $3.5 \mathrm{~cm}$ were supplemented with $7.5 \mathrm{ml}$ or $0.9 \mathrm{ml}$ of cell suspension, respectively. Petri dishes with a diameter of $9.2 \mathrm{~cm}$ were used to study the degradation of CDC over $24 \mathrm{~h}$. To maintain the sand/liquid ratio, samples containing cell suspension and sand were repeatedly withdrawn from the same petri dish, centrifuged at $>16,000 \times g$ for $5 \mathrm{~min}$, with the supernatants used for HPLC-MS measurements. Petri dishes with a diameter of $3.5 \mathrm{~cm}$ were used to monitor the degradation of CDC over prolonged time periods and in the presence of $10 \mathrm{C}$. elegans non-synchronized adult worms on each petri dish. These petri dishes were incubated in darkness for up to five days at $21^{\circ} \mathrm{C}$ and weighed every day to determine water loss. Freshly prepared cell suspensions were added daily to compensate for a loss of water and to provide fresh and active bacteria. At several time points, the supernatant of one petri dish each was withdrawn for LC-MS analysis.

Fecundity of $C$. elegans in sand microcosms. Sand microcosms were prepared by filling $3 \mathrm{~g}$ of sterilized quartz sand into petri dishes $(\varnothing: 3.5 \mathrm{~cm})$. The water-holding capacity of the sand was determined at room temperature $(\sim 24 \%)$ and after two days at $60^{\circ} \mathrm{C}(\sim 35 \%)$. From these results, a mean value of $30 \%$ was chosen, and $900 \mu \mathrm{l}$ of cell suspension (MMChol media with bacteria and, if applicable, with $0.25 \mathrm{mM}$ of CDC) were added to the sand. Worms were fed with E. coli OP50 $0_{\text {-ura }}$ and P. stutzeri Chol1. Preliminary experiments revealed a final E. coli OP50 ${ }_{\text {-ura }}$ concentration of $\mathrm{OD}_{600}=0.6$ in the cell suspension as optimum feeding quantity because the reproduction of C. elegans over 4 -day periods did not increase anymore with more E. coli OP50 ${ }_{\text {-ura }}$ provided. As $P$. stutzeri Chol1 was applied at a final concentration of $\mathrm{OD}_{600}=0.013$, experiments without $P$. stutzeri Choll were carried out at a final E. coli OP50 $0_{\text {-ura }}$ concentration of $\mathrm{OD}_{600}=0.613$. After inserting one C. elegans $\mathrm{L} 4$ worm in a 
liquid-filled gap in the sand sample, the samples were incubated for four days at $21^{\circ} \mathrm{C} .100 \mu$ lof fresh cell suspension with $1.25 \mathrm{mM}$ of CDC, if applicable, were added daily.

After incubation, the offspring of the worm was extracted from sand using a modification of the centrifugal flotation method ${ }^{84}$ using Ludox (LUDOX ${ }^{\circledR}$ HS-40 colloidal silica; Sigma-Aldrich Chemie GmbH, Munich, Germany). $2 \mathrm{ml}$ of a Ludox/M9 buffer solution (1:1) was pipetted onto the sand, which was slightly tilted. $4 \times 500 \mu \mathrm{l}$ of the liquid phase were then transferred to 4 Eppendorf tubes filled with $1 \mathrm{ml}$ of M9 buffer ${ }^{77}$. These samples were centrifuged $\left(2,700 \times g, 1 \mathrm{~min}, 20^{\circ} \mathrm{C}\right)$ and allowed to stand for $10 \mathrm{~min}$. This extraction step was repeated another 3 times, resulting in 16 tubes. During the last application of the Ludox/M9 buffer, the sand was checked for worms. After transferring slightly more than $1 \mathrm{ml}$ of the supernatants of the 16 samples into small petri dishes, living worms were counted. The remaining rests of the samples were united, resulting in 4 tubes. These samples were centrifuged and allowed to stand for at least $5 \mathrm{~min}$. Using $1 \mathrm{ml}$ of the supernatants, worms were again counted. After the addition of $1 \mathrm{ml}$ of $\mathrm{M} 9$ buffer to each tube, centrifugation and a rest period of at least $5 \mathrm{~min}$, the worms in $1 \mathrm{ml}$ of the supernatants were again counted. The remaining rests of the 4 tubes were then transferred onto NGM plates, where worms were again counted. The effects of four different experimental conditions on the reproduction of $C$. elegans were tested in three independent experimental series. As the number of offspring varied considerably from series to series, the data of each experimental series were normalized (i.e., division by the mean number of offspring of each experimental series).

Statistics. Data are given as means \pm standard deviation (sd) or standard error (se). $n$ indicates the number of biological replicates and $N$ the number of animals used. SigmaPlot 11.0 (Systat Software, Erkrath, Germany) was used for graph preparation and statistical analysis. Statistical significances ( $P$ values $)$ were calculated using one-, two-, or three-way analyses of variance (ANOVA) and subsequent Student-Newman-Keuls analyses, chi-square analyses, or t-tests.

\section{Data Availability}

The data analysed during this study are included in this published article (and its Supplementary Information files). The transcriptomic data are publically available from the NCBI Gene Expression Omnibus (GEO) under the accession number GSE126214.

\section{References}

1. Hanselman, T. A., Graetz, D. A. \& Wilkie, A. C. Manure-borne estrogens as potential environmental contaminants: A review. Environ. Sci. Technol. 37, 5471-5478 (2003).

2. Tyagi, P., Edwards, D. R. \& Coyne, M. S. Use of sterol and bile acid biomarkers to identify domesticated animal sources of fecal pollution. Water. Air. Soil Pollut. 187, 263-274 (2008).

3. Elhmmali, M. M., Roberts, D. J. \& Evershed, R. P. Bile acids as a new class of sewage pollution indicator. Environ. Sci. Technol. 31, 3663-3668 (1997).

4. Bull, I. D., Lockheart, M. J., Elhmmali, M. M., Roberts, D. J. \& Evershed, R. P. The origin of faeces by means of biomarker detection. Environ. Int. 27, 647-654 (2002).

5. Hofmann, A. F. \& Hagey, L. R. Bile acids: Chemistry, pathochemistry, biology, pathobiology, and therapeutics. Cell. Mol. Life Sci. 65, 2461-2483 (2008).

6. Vítek, L. \& Haluzík, M. The role of bile acids in metabolic regulation. J. Endocrinol 228, R85-R96 (2016).

7. Maldonado-Valderrama, J., Wilde, P., MacIerzanka, A. \& MacKie, A. The role of bile salts in digestion. Adv. Colloid Interface Sci. 165, 36-46 (2011).

8. Ridlon, J. M., Kang, D.-J. J. \& Hylemon, P. B. Bile salt biotransformations by human intestinal bacteria. J. Lipid Res. 47, 241-259 (2006).

9. Tyagi, P., Edwards, D. R. \& Coyne, M. S. Fecal sterol and bile acid biomarkers: Runoff concentrations in animal waste-amended pastures. Water. Air. Soil Pollut. 198, 45-54 (2009).

10. Elhmmali, M. M., Roberts, D. J. \& Evershed, R. P. Combined analysis of bile acids and sterols/stanols from riverine particulates to assess sewage discharges and other fecal sources. Environ. Sci. Technol. 34, 39-46 (2000).

11. Holert, J. et al. Evidence of distinct pathways for bacterial degradation of the steroid compound cholate suggests the potential for metabolic interactions by interspecies cross-feeding. Environ. Microbiol. 16, 1424-1440 (2014).

12. Philipp, B., Erdbrink, H., Suter, M. J. F. \& Schink, B. Degradation of and sensitivity to cholate in Pseudomonas sp. strain Chol1. Arch. Microbiol. 185, 192-201 (2006).

13. Merino, E. et al. Isolation of cholesterol- and deoxycholate-degrading bacteria from soil samples: Evidence of a common pathway. Appl. Microbiol. Biotechnol. 97, 891-904 (2013).

14. Hayakawa, S. Microbial transformation of bile acids. A unified scheme for bile acid degradation, and hydroxylation of bile acids. $Z$. Allg. Mikrobiol 22, 309-326 (2007).

15. Philipp, B. Bacterial degradation of bile salts. Appl. Microbiol. Biotechnol. 89, 903-915 (2011).

16. Galán, B., García-Fernández, J., Felpeto-Santero, C., Fernández-Cabezón, L. \& García, J. L. Baterial metabolism of steroids in Aerobic Utilization of Hydrocarbons, Oils and Lipids (ed. Rojo, F.) 1-22 (Springer International Publishing, 2017).

17. Horinouchi, M., Hayashi, T. \& Kudo, T. Steroid degradation in Comamonas testosteroni. J. Steroid Biochem. Mol. Biol. 129, 4-14 (2012).

18. Maser, E., Xiong, G., Grimm, C., Ficner, R. \& Reuter, K. $3 \alpha$-hydroxysteroid dehydrogenase/carbonyl reductase from Comamonas testosteroni: Biological significance, three-dimensional structure and gene regulation. Chem. Biol. Interact. 130-132, 707-722 (2001).

19. Birkenmaier, A. et al. Biochemical and genetic investigation of initial reactions in aerobic degradation of the bile acid cholate in Pseudomonas sp. strain Chol1. J. Bacteriol. 189, 7165-7173 (2007).

20. Wipperman, M. F., Sampson, N. S. \& Thomas, S. T. Pathogen roid rage: Cholesterol utilization by Mycobacterium tuberculosis. Crit. Rev. Biochem. Mol. Biol. 49, 269-93 (2014).

21. Petrusma, M., Van Der Geize, R. \& Dijkhuizen, L. 3-Ketosteroid $9 \alpha$-hydroxylase enzymes: Rieske non-heme monooxygenases essential for bacterial steroid degradation. Antonie Van Leeuwenhoek 106, 157-172 (2014).

22. Park, R. J., Dunn, N. W. \& Ide, J. A. A catecholic 9,10- seco steroid as a product of aerobic catabolism of cholic acid by a Pseudomonas sp. Steroids 48, 439-450 (1986).

23. Crowe, A. M. et al. Catabolism of the last two steroid rings in Mycobacterium tuberculosis and other bacteria. MBio 8, 1-16 (2017). 
24. Swain, K., Casabon, I., Eltis, L. D. \& Mohn, W. W. Two transporters essential for reassimilation of novel cholate metabolites by Rhodococcus jostii RHA1. J. Bacteriol. 194, 6720-6727 (2012).

25. Bhasin, S. \& Jasuja, R. Pharmacological analysis of boldione and 19-nor-4,9(10)-androstadienedione for androgenic activity using C3H10T1/2 stem cells. Unpubl. Rep., https://www.regulations.gov/docket?D=DEA-2008-0007 (2005).

26. Matsumoto, A. M. \& Marck, B. T. DEA Agreement No. DEA-04- P0007 Final Report [Analysis of the androgenic and anabolic activities of 1,4-androstadien- 3,17-dione and 19-nor-4,9(10)- androstadienedione in male Sprague Dawley rats]. Unpubl. Rep., https://www.regulations.gov/docket? D=DEA-2008-0007 (2006).

27. Broeder, C. E. C. et al. The Andro Project - Physiological and hormonal influences of androstenedione supplementation in men 35 to 65 years old participating in a high-intensity resistance training program. Arch Intern Med 160, 3093-3104 (2000).

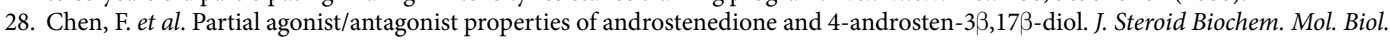
91, 247-257 (2004)

29. Hou, L., Xie, Y., Ying, G. \& Fang, Z. Developmental and reproductive characteristics of western mosquitofish (Gambusia affinis) exposed to paper mill effluent in the Dengcun River, Sihui, South China. Aquat. Toxicol. 103, 140-149 (2011).

30. Brockmeier, E. K., Jayasinghe, B. S., Pine, W. E., Wilkinson, K. A. \& Denslow, N. D. Exposure to paper mill effluent at a site in north central Florida elicits molecular-level changes in gene expression indicative of progesterone and androgen exposure. PLoS One 9 , e106644 (2014)

31. Parks, L. G. et al. Masculinization of female mosquitofish in kraft mill effluent-contaminated fenholloway river water is associated with androgen receptor agonist activity. Toxicol. Sci 62, 257-267 (2001).

32. Custodia, N. et al. Caenorhabditis elegans as an environmental monitor using DNA microarray analysis. Ann. N. Y. Acad. Sci. 948, 32-42 (2001).

33. Fernandes, D., Loi, B. \& Porte, C. Biosynthesis and metabolism of steroids in molluscs. J. Steroid Biochem. Mol. Biol. 127, 189-195 (2011).

34. Scott, A. P. Do mollusks use vertebrate sex steroids as reproductive hormones? Part I: Critical appraisal of the evidence for the presence, biosynthesis and uptake of steroids. Steroids 77, 1450-1468 (2012).

35. Scott, A. P. Do mollusks use vertebrate sex steroids as reproductive hormones? II. Critical review of the evidence that steroids have biological effects. Steroids 78, 268-281 (2013).

36. Hirschmann, H. Die Nematoden der Wassergrenze mittelfränkischer Gewässer. In Zoologisches Jahrbuch, Abteilung für Systematik 371-374 (1952).

37. Yeates, G. W. Nematodes in ecological webs. In Encyclopedia of Life Sciences (John Wiley \& Sons, Ltd., 2010).

38. Schulenburg, H. \& Félix, M. A. The natural biotic environment of Caenorhabditis elegans. Genetics 206, 55-86 (2017).

39. Kaletta, T. \& Hengartner, M. O. Finding function in novel targets: C. elegans as a model organism. Nat. Rev. Drug Discov. 5, 387-399 (2006).

40. Olsen, A. \& Gill, M. (eds) Ageing: Lessons from C. elegans. (Springer International Publishing, 2017).

41. Wilson, M. \& Kakouli-Duarte, T. (eds) Nematodes as environmental indicators. (CABI, 2009).

42. Hägerbäumer, A., Höss, S., Heininger, P. \& Traunspurger, W. Experimental studies with nematodes in ecotoxicology: An overview. J. Nematol. 47, 11-27 (2015).

43. Menzel, R., Steinberg, C. E. W. \& Stürzenbaum, S. R. Caenorhabditis elegans and chemical environmental stressors: From DNA microarrays and data analysis to genomic data of true ecotoxicological relevance in nematodes as environmental indicators (eds Wilson, M. \& Kakouli-Duarte, T.) 253-274 (CABI 2009).

44. Hulme, S. E. \& Whitesides, G. M. Chemistry and the worm: Caenorhabditis elegans as a platform for integrating chemical and biological research. Angew. Chemie Int. Ed. 50, 4774-4807 (2011).

45. Sluder, A. E. \& Maina, C. V. Nuclear receptors in nematodes: Themes and variations. Trends Genet 17, 206-213 (2001).

46. Gissendanner, C. R. et al. C. elegans nuclear receptor NHR-6 functionally interacts with the jun-1 transcription factor during spermatheca development. genesis 52, 29-38 (2014).

47. Gáliková, M., Klepsatel, P., Senti, G. \& Flatt, T. Steroid hormone regulation of C. elegans and Drosophila aging and life history. Exp. Gerontol. 46, 141-147 (2011).

48. Gámez-Del-Estal, M. M., Contreras, I., Prieto-Pérez, R. \& Ruiz-Rubio, M. Epigenetic effect of testosterone in the behavior of $C$. elegans. A clue to explain androgen-dependent autistic traits? Front. Cell. Neurosci 8, 69 (2014).

49. Mimoto, A. et al. Identification of an estrogenic hormone receptor in Caenorhabditis elegans. Biochem. Biophys. Res. Commun. 364, 883-888 (2007)

50. Hieb, W. F. \& Rothstein, M. Sterol requirement for reproduction of a free-living nematode. Science 160, 778-80 (1968).

51. Chitwood, D. J. Biochemistry and function of nematode steroids. Crit. Rev. Biochem. Mol. Biol. 34, 273-284 (1999).

52. Motola, D. L. et al. Identification of ligands for DAF-12 that govern dauer formation and reproduction in C. elegans. Cell 124, 1209-1223 (2006).

53. Tominaga, N. et al. Caenorhabditis elegans responses to specific steroid hormones. J. Heal. Sci. 49, 28-33 (2003).

54. Holert, J. et al. Identification of bypass reactions leading to the formation of one central steroid degradation intermediate in metabolism of different bile salts in Pseudomonas sp. strain Chol1. Environ. Microbiol. 18, 3373-3389 (2016).

55. Van Voorhies, W. A., Fuchs, J. \& Thomas, S. The longevity of Caenorhabditis elegans in soil. Biol. Lett. 1, 247-9 (2005).

56. Chalfie, M. et al. The neural circuit for touch sensitivity in Caenorhabditis elegans. J. Neurosci., https://doi.org/3981252 (1985).

57. Kim, D. H. et al. A conserved p38 MAP kinase pathway in Caenorhabditis elegans innate immunity. Science 297, 623-626 (2002).

58. Troemel, E. R. et al. p38 MAPK Regulates expression of immune response genes and contributes to longevity in C. elegans. PLoS Genet. 2, e183(2006)

59. Cremers, C. M., Knoefler, D., Vitvitsky, V., Banerjee, R. \& Jakob, U. Bile salts act as effective protein-unfolding agents and instigators of disulfide stress in vivo. Proc. Natl. Acad. Sci. USA 111, E1610-9 (2014).

60. Begley, M., Gahan, C. G. M. \& Hill, C. The interaction between bacteria and bile. FEMS Microbiol. Rev. 29, 625-651 (2005).

61. Hay, A. J. \& Zhu, J. In sickness and in health: The relationships between bateria and bile in the human gut. Adv. Appl. Microbiol 96, 43-64 (2016)

62. Combalbert, S. et al. Fate of steroid hormones and endocrine activities in swine manure disposal and treatment facilities. Water Res 46, 895-906 (2012).

63. Lai, K. M., Johnson, K. L., Scrimshaw, M. D. \& Lester, J. N. Binding of waterborne steroid estrogens to solid phases in river and estuarine systems. Environ. Sci. Technol. 34, 3890-3894 (2000).

64. Macneil, L. T. \& Walhout, A. J. Food, pathogen, signal: The multifaceted nature of a bacterial diet. Worm 2, e26454 (2013).

65. Gerisch, B. et al. A bile acid-like steroid modulates Caenorhabditis elegans lifespan through nuclear receptor signaling. Proc. Natl. Acad. Sci. USA 104, 5014-9 (2007).

66. Lai, D. et al. 9,10-Secosteroids, protein kinase inhibitors from the Chinese gorgonian Astrogorgia sp. Bioorg. Med. Chem. 19, 6873-6880 (2011).

67. Holert, J. et al. Metagenomes reveal global distribution of bacterial steroid catabolism in natural, engineered, and host environments. MBio 9, e02345-17 (2018)

68. Bergstrand, L. H., Cardenas, E., Holert, J., van Hamme, J. D. \& Mohn, W. W. Delineation of steroid-degrading microorganisms through comparative genomic analysis. MBio 7, 1-14 (2016). 
69. Yücel, O., Drees, S., Jagmann, N., Patschkowski, T. \& Philipp, B. An unexplored pathway for degradation of cholate requires a $7 \alpha$-hydroxysteroid dehydratase and contributes to a broad metabolic repertoire for the utilization of bile salts in Novosphingobium sp. strain Chol11. Environ. Microbiol. 18, 5187-5203 (2016).

70. Yücel, O., Holert, J., Ludwig, K. C., Thierbach, S. \& Philipp, B. A novel steroidcoenzyme A ligase from Novosphingobium sp. strain Chol11 is essential for an alternative degradation pathway for bile salts. Appl. Environ. Microbiol. 84, 1-16 (2018).

71. Warnke, M. et al. A patchwork pathway for oxygenase-independent degradation of side chain containing steroids. Environ. Microbiol. 19, 4684-4699 (2017).

72. Yücel, O., Borgert, S. R., Poehlein, A., Niermann, K. \& Philipp, B. The $7 \alpha$-hydroxysteroid dehydratase Hsh2 is essential for anaerobic degradation of the steroid skeleton of $7 \alpha$-hydroxyl bile salts in the novel denitrifying bacterium Azoarcus sp. strain Aa7. Environ. Microbiol., https://doi.org/10.1111/1462-2920.14508 (2018).

73. Hallmann, C. A. et al. More than 75 percent decline over 27 years in total flying insect biomass in protected areas. PLoS One 12, e0185809 (2017).

74. Dirzo, R. et al. Defaunation in the anthropocene. Science 345, 401-6 (2014).

75. Benton, T. G., Bryant, D. M., Cole, L. \& Crick, H. Q. P. Linking agricultural practice to insect and bird populations: A historical study over three decades. J. Appl. Ecol. 39, 673-687 (2002).

76. Bertani, G. Studies on lysogenesis. I. The mode of phage liberation by lysogenic. Escherichia coli. J. Bacteriol. 62, 293-300 (1951).

77. Stiernagle, T. Maintenance of C. elegans. Worm Book (2006).

78. Holert, J. et al. Degradation of the acyl side chain of the steroid compound cholate in Pseudomonas sp. strain Choll proceeds via an aldehyde intermediate. J. Bacteriol. 195, 585-595 (2013).

79. Bounoutas, A. \& Chalfie, M. Touch sensitivity in Caenorhabditis elegans. Pflügers Arch. - Eur. J. Physiol. 454, 691-702 (2007).

80. Mertenskötter, A., Keshet, A., Gerke, P. \& Paul, R. J. The p38 MAPK PMK-1 shows heat-induced nuclear translocation, supports chaperone expression, and affects the heat tolerance of Caenorhabditis elegans. Cell Stress Chaperones 18, 293-306 (2013).

81. Keshet, A. et al. PMK-1 p38 MAPK promotes cadmium stress resistance, the expression of SKN-1/Nrf and DAF-16 target genes, and protein biosynthesis in Caenorhabditis elegans. Mol. Genet. Genomics 292, 1341-1361 (2017).

82. Mortazavi, A., Williams, B. A., McCue, K., Schaeffer, L. \& Wold, B. Mapping and quantifying mammalian transcriptomes by RNASeq. Nat. Methods 5, 621-628 (2008).

83. Tarazona, S., García-Alcalde, F., Dopazo, J., Ferrer, A. \& Conesa, A. Differential expression in RNA-seq: A matter of depth. Genome Res. 21, 2213-2223, https://doi.org/10.1101/gr.124321.111 (2011).

84. Hooper, D. J. \& Southey, J. F. Extraction of free-living stages from soil. In Laboratory Methods for Work with Plant and Soil Nematodes. (ed. Southey, J. F.) 5-30 (H. M. S. O. Books, 1986).

\section{Acknowledgements}

We thank Karin Topp and Andrea Schwalb (Institute of Zoophysiology, WWU Münster) for supporting measurements and data sets. This work was supported by the Deutsche Forschungsgemeinschaft (DFG grants Pa 308/13-1, PH71/3-2 and INST 211/646-1 FUGG).

\section{Author Contributions}

Each author has materially participated in the research and/or preparation and has approved the final article. Study design: M.N.M., R.D., R.J.P., F.F., B.P. Test realization: M.N.M., R.D., F.F., K.L., O.Y., D.H., A.M., L.R.F. Data analysis: M.N.M., R.D., R.J.P., F.F., B.P. Data interpretation: M.N.M., R.D., R.J.P., F.F., B.P. Manuscript preparation: M.N.M., R.J.P., F.F., B.P.

\section{Additional Information}

Supplementary information accompanies this paper at https://doi.org/10.1038/s41598-019-47476-y.

Competing Interests: The authors declare no competing interests.

Publisher's note: Springer Nature remains neutral with regard to jurisdictional claims in published maps and institutional affiliations.

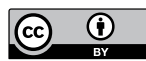

Open Access This article is licensed under a Creative Commons Attribution 4.0 International

License, which permits use, sharing, adaptation, distribution and reproduction in any medium or format, as long as you give appropriate credit to the original author(s) and the source, provide a link to the Creative Commons license, and indicate if changes were made. The images or other third party material in this article are included in the article's Creative Commons license, unless indicated otherwise in a credit line to the material. If material is not included in the article's Creative Commons license and your intended use is not permitted by statutory regulation or exceeds the permitted use, you will need to obtain permission directly from the copyright holder. To view a copy of this license, visit http://creativecommons.org/licenses/by/4.0/.

(C) The Author(s) 2019 